\title{
The Evolving Systemic and Local Biomarker Milieu at Different Stages of Disease Progression in Rat Adjuvant-Induced Arthritis
}

\author{
Marina Stolina • Brad Bolon • Scot Middleton • \\ Denise Dwyer • Heather Brown • Diane Duryea • \\ Li Zhu • Alison Rohner • James Pretorius • \\ Paul Kostenuik • Ulrich Feige $\cdot$ Debra Zack
}

Received: 14 February 2008 / Accepted: 4 August 2008 /Published online: 26 August 2008

(C) The Author(s) 2008. This article is published with open access at Springerlink.com

\begin{abstract}
Introduction Rats with adjuvant-induced arthritis (AIA) were necropsied on 14 occasions during preclinical, acute clinical and chronic clinical stages of AIA progression to characterize local (joint protein extracts) and systemic (serum) levels of mediators regulating inflammation and bone erosion in conjunction with lymphoid tissue-specific leukocyte kinetics.

Results Systemic increases in alphal acid glycoprotein, tumor necrosis factor- $\alpha$ (TNF $\alpha$ ), interleukin (IL)-17, transforming growth factor beta (TGF $\beta$ ), and chemokine (C-C motif) ligand 2 (CCL2) together with local IL-1 $\alpha / \beta$ and
\end{abstract}

M. Stolina $(\triangle) \cdot$ D. Dwyer $\cdot$ P. Kostenuik

Department of Metabolic Disorders, Amgen,

One Amgen Center Drive, M/S 15-2-A,

Thousand Oaks, CA 91320-1799, USA

e-mail: mstolina@amgen.com

B. Bolon $\cdot$ D. Duryea $\cdot$ J. Pretorius

Department of Pathology, Amgen,

Thousand Oaks, CA, USA

S. Middleton $\cdot$ H. Brown $\cdot$ L. Zhu $\cdot$ A. Rohner $\cdot$ U. Feige $\cdot$ D. Zack

Department of Inflammation, Amgen,

Thousand Oaks, CA, USA

Present address:

B. Bolon

GEMpath,

Longmont, CO, USA

Present address:

U. Feige

EUROCBI GmbH,

Benglen,

Zurich, Switzerland
TGF $\beta$ enrichment and local lymphoid hyperplasia preceded the onset of clinical disease and joint damage. Systemic upregulation of TNF $\alpha$, IL-6, IL-17, TGF $\beta$, IL-18, CCL2, receptor activator of nuclear factor- $\kappa \beta$ ligand (RANKL), and prostaglandin $\mathrm{E}_{2}$ during acute and/or chronic AIA coincided with systemic leukocytosis and CD4+ T cell increase in blood and spleen. In contrast, progression of joint erosions during clinical AIA was associated with intraarticular increases in IL- $1 \alpha / \beta$, IL-6, RANKL, IL-17, TGF $\beta$, CCL2, and KC/GRO and also a dramatic decline in osteoprotegerin.

Conclusion These data indicate that systemic and local events in inflammatory arthritis are discrete processes, driven by multiple cellular and humoral mediators with distinct kinetic profiles.

Keywords Rat adjuvant-induced arthritis · cytokines · biomarkers $\cdot$ inflammation $\cdot$ bone resorption

\section{Introduction}

Rheumatoid arthritis (RA) is an immune-mediated disease that targets the synovial membrane, articular cartilage, and bone. The pathogenesis of RA is autoimmunity that drives chronic soft tissue inflammation and eventually joint destruction. Production of rheumatoid factors (antibodies specific for $\operatorname{IgG}$ ) and/or antibodies directed to cyclic citrullinated peptides often precedes the clinically detectable onset of human RA [1]. Immune-mediated joint damage is instigated and perpetuated by the release of many pro-inflammatory cytokines $[2,3]$. However, it is still not clear (1) how cytokine networks are organized within 
systemic and/or local compartments and (2) which cytokines might be the best targets for clinical intervention at different stages of arthritis progression.

The foremost contributors in patients with rheumatoid arthritis and related spondyloarthropathies are interleukin-1 (IL-1; chiefly the inducible $\beta$ form) and tumor necrosis factor- $\alpha(\mathrm{TNF} \alpha)$ [4-7]. Their central importance is demonstrated by the ability of anti-IL-1 or anti-TNF- $\alpha$ biologics to reduce clinical and structural measures of disease in arthritic patients $[8,9]$ and animals with induced arthritis [10-15]. For this reason, cytokine inhibitors that block the action of IL-1 or TNF- $\alpha$ are widely used to treat rheumatoid arthritis and other immune-mediated skeletal diseases [16-18].

IL-1 and TNF $\alpha$ act synergistically $[11,19]$ to maintain inflammation and bone erosions in animal models of joint inflammation, including adjuvant-induced arthritis (AIA) in rats $[11,12,20-22]$. However, while inhibition of IL-1, $\mathrm{TNF} \alpha$, or both yields a significant anti-inflammatory effect in rats with AIA, residual disease persists [11, 23, 24]. Such lingering inflammation might be related to submaximal inhibition of the intended targets or, alternatively, to potential contributions by other pro-inflammatory cytokines (e.g., IL-6, IL-12, IL-15, IL-17, IL-18 $[25,26]$ ) and chemokines (e.g., chemokine $(\mathrm{C}-\mathrm{C}$ motif) ligand 2 (CCL2) [formerly monocyte chemotactic protein-1 [27]], CXC chemokine ligand 8 (CXCL8) [formerly IL-8 [28]]). One or more of these same molecules could represent additional etiologic factors in the initiation and/or progression of immune-mediated arthritis. This notion is supported by the variable responses achieved in human arthritis patients using existing anticytokine biologics [29-31].

In addition to pro-inflammatory molecules, specific regulators of bone resorption such as receptor activator of nuclear factor- $\mathrm{k} \beta$ ligand (RANKL; a primary mediator of osteoclast formation, function, and survival) and its soluble decoy receptor osteoprotegerin (OPG) also play important roles in immune-mediated joint disease via their ability to regulate intra-articular osteoclasts [32]. Focal bone erosion in inflamed joints is a hallmark of immune-mediated arthritis and has been attributed to excessive RANKLmediated osteoclast activity [33-35]. In animal models, recombinant osteoprotegerin showed anti-erosive effects in rats with clinical adjuvant- or collagen-induced arthritis [34, $36]$ and inhibited inflammatory bone loss and erosions in tumor necrosis factor-transgenic mice [37, 38]. Treatment of RA patients with denosumab, a fully human monoclonal antibody that binds and inhibits RANKL, increased bone mineral density and inhibited RA-related skeletal structural damage and erosions [39].

To evaluate targets for therapeutic intervention, it is important to understand the spatial and temporal expression patterns of the myriad factors that have been implicated in
RA progression. While peripheral blood provides an expedient source to assess systemic levels of these factors, joint tissue can also provide important information on local changes [40-42]. Data comparing local versus systemic levels of markers and mediators of RA progression are rare in the literature. However, some of the existing reports describe divergent levels when comparing for local and systemic compartments [42-44]. These reports highlight the likelihood that systemic markers and mediators of arthritis might not fully reflect the underlying local disease progression. Basing treatment decisions in such a scenario on systemic cytokine levels would have a negative impact on the identification of patients who might benefit from early intervention and on the choice of appropriate therapeutics.

We performed the current work in a standard rat adjuvant-induced arthritis model to explore the evolution of the cytokine spectrum over time in both the local (joint and regional lymph nodes) and systemic (circulation and distant lymphoid tissues) compartments. We hypothesized that the AIA would be associated with distinct cytokine profiles in the systemic circulation versus the local sites of inflammation (affected paws). We also hypothesized that pro-inflammatory molecules other than IL- $1 \beta$ and TNF $\alpha$ would surface as potentially major players (and useful biomarkers) in launching and sustaining arthritis. Our present data show that cytokine profiles in immunemediated arthritis differ substantially in the local and systemic settings and indicate that elevated intra-articular IL-17 may be a significant driver of local joint destruction.

\section{Materials and Methods}

These studies were conducted in accordance with federal animal care guidelines and were preapproved by Amgen's Institutional Animal Care and Use Committee.

\section{Experimental Design}

Rat AIA is a well-characterized model for assessing arthritis mechanisms [10, 11, 23, 24, 34, 45, 46]. For this study, disease was investigated by taking clinical measurements as well as fluid (serum) and tissue (hind paws, femur, lymphoid organs) samples on 14 occasions: before onset $(-5,-3$, or -1 days), at onset (indicated by hind paw swelling and ambulatory difficulties), and during clinical arthritis progression $(+1,+2,+3,+4,+5,+7,+10,+14,+20$, and +27 days after onset).

Animals

Male Lewis rats (7 to 8 weeks old; Charles River, Wilmington, MA, USA) were acclimated for 1 week and 
then randomly assigned to treatments (14 AIA groups with $n=8$ per time point and 28 nonarthritic controls [two per time point]). This cohort size was used because interindividual variability is minimal between untreated rats with AIA [11]. Animals received tap water and pelleted chow (\#8640, Harlan Teklad, Madison, WI) ad libitum; calcium and phosphorus were $1.2 \%$ and $1.0 \%$, respectively.

Induction of Arthritis

AIA was induced as described [11] by a single intradermal injection at the tail base of heat-killed Mycobacterium tuberculosis H37Ra (0.5 mg; Difco Laboratories, Detroit, MI, USA) suspended in $0.05 \mathrm{ml}$ paraffin oil (Crescent Chemical Co., Hauppauge, NY, USA). The day of disease induction was designated as study day 0 .

\section{Assessment of Arthritis}

Clinical Evaluation Total body weights were gathered to assess general health. Joint swelling was examined by measuring average hind paw volume via water plethysmography [11] or diameter via precision calipers [42].

Hematologic Assessment At necropsy, blood was collected by intracardiac puncture from rats anesthetized with $\mathrm{CO}_{2}$. A complete blood count was acquired from ethylenediaminetetraacetic acid-treated whole blood using an Advia 120 analyzer (Bayer Corporation, Tarrytown, NY, USA). Flow cytometry (FACSCalibur; BD Biosciences, San Jose, CA, USA) to quantify leukocyte subpopulations was performed on whole blood and selected local (popliteal and inguinal lymph nodes) and systemic (mesenteric lymph node and spleen) lymphoid organs (dissociated in PBS) using antibody reagents (BD PharMingen, San Diego, CA, USA) directed against cell surface markers specific for $\mathrm{B}$ (CD45RA) and T (CD3, CD4, CD8) lymphocytes, antigenpresenting cells $(\mathrm{CD} 11 \mathrm{~b} / \mathrm{c})$, granulocytes (HIS48), and macrophages (HIS36).

Protein Extraction from Joints One tibiotarsal region from one hind paw was flash-frozen, pulverized, and extracted using a 50-mM Tris buffer, $\mathrm{pH} 7.4$, containing $0.1 \mathrm{M} \mathrm{NaCl}$ and $0.1 \%$ Triton $\mathrm{X}-100$. Protein concentration in individual extracts was evaluated using a standard BCA Protein Assay (Pierce Co., Rockford, IL, USA).

Biochemical Assays for Serum and Joint Extracts Separate aliquots of serum or paw protein extracts were used to quantify levels of various analytes. The major rat acute phase protein alpha1 acid glycoprotein ( $\alpha 1$ AGP) was measured by a precipitin ring assay (Ecos Institute, Furukawa, Miyagi, Japan). Multiple cytokines (IL- $1 \alpha / \beta, \mathrm{TNF} \alpha$, transforming growth factor beta (TGF $\beta$ ), IL-2, IL-4, IL-10, IL-12, I IL-17, IL-18, IL-6, CCL2, KC/GRO, granulocyte monocyte colonystimulating factor (GM-CSF), interferon (IFN) $\gamma$, RANKL) were assessed using multiplex rat-specific Luminex kits (Linco Research, St. Charles, MO, USA), or single-plex mouse OPG-specific Luminex kits (Linco Research, St. Charles, MO, USA); the mouse OPG kit was $95 \%$ to $98 \%$ cross-reactive with rat OPG based on a comparison of standard curves for recombinant mouse OPG (internal kit standard) vs. recombinant rat OPG (Amgen Inc., Thousand Oaks, CA, USA). Prostaglandin $\mathrm{E}_{2}\left(\mathrm{PGE}_{2}\right)$ was evaluated using an enzyme immunoassay kit (Cayman Chemical, Ann Arbor, MI, USA). Total immunoglobulins were determined by enzyme-linked immunosorbent assay (Bethyl Laboratories, Montgomery, TX, USA). Concentrations of humoral immune modulators in paw protein extracts were evaluated as described above and normalized to the total protein concentration. Assays were performed according to the manufacturers' instructions.

Histopathology The other hind paw was removed, fixed by immersion in zinc formalin, decalcified in eight serial changes of a $1: 4$ mixture of $8 \mathrm{~N}$ formic acid and $1 \mathrm{~N}$ sodium formate for approximately a week, trimmed, and processed into paraffin. The extent of local disease was evaluated in the paw at all time points using standard criteria and a blinded analytical paradigm (Table I; [11]). Analyses were done in sections stained with hematoxylin and eosin (H\&E).

Detection of TNF $\alpha$ Expression in Joint Tissue by In Situ Hybridization Additional serial 5- $\mu$ m-thick hind paw sections of the nonarthritic control and AIA cohorts were processed using a conventional in situ hybridization (ISH) protocol to localize TNF $\alpha$. A 185-bp DNA fragment of the rat $\mathrm{TNF} \alpha$ gene, corresponding to nucleotides 2115-2300 (GenBank \#D00475) was cloned into the pGEM-T vector (Promega Corp., Madison, WI, USA) for use as a template. An antisense ${ }^{33} \mathrm{P}$-labeled RNA probe was synthesized with Sp6 RNA polymerase after linearization with BamHI restriction enzyme. The TNF $\alpha$ riboprobe produced strong signal in the positive control tissue (colon from B7RP1 mouse colitis model [47]), indicating that the probe was sound. Hind paw sections were hybridized with the probe overnight at $60^{\circ} \mathrm{C}$, followed by RNase digestion and a series of SSC washes with highest stringency of 0.1X SSC at $55^{\circ} \mathrm{C}$ for $30 \mathrm{~min}$. Slides were subsequently air-dried and exposed on a phosphor screen overnight. Screens were scanned with a Storm 840 PhosphorImager (GE Healthcare, Piscataway, NJ, USA), but the signal was not quantified. Finally, the slides were coated with NTB2 emulsion (Kodak, Rochester, NY) and exposed for 3 weeks in the dark at approximately $4^{\circ} \mathrm{C}$, developed, and then counter- 
Table I Histopathology Criteria for Scoring Joint Lesions

Histopathology criteria

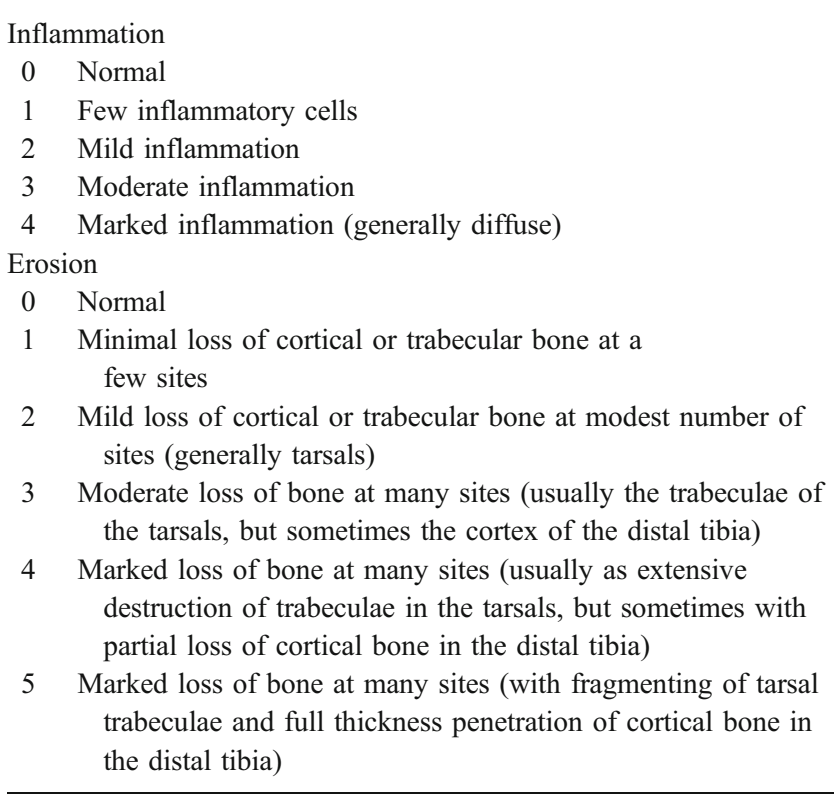

stained with H\&E. Degree of expression in each slide was subjectively evaluated under dark field microscopy, and ISH signal intensity was assessed using a semiquantitative grading scale: $(-)=$ no signal, $(+/-)=$ equivocal, $(+)=$ weak $/$ low, $(++)=$ moderate, and $(+++)=$ strong.

Statistical Analysis Results are expressed as mean \pm standard error of the mean (SEM). Student's $t$ test was used for the clinical data by comparing AIA vs. control rats. Histopathology data were analyzed using the chi-square test. Statistical significance was delineated by a $p$ value $<$ 0.05 .

\section{Results}

\section{Arthritis Progression}

The clinical progression of AIA followed the typical course described previously [11]. Briefly, clinical onset of AIA in all animals occurred on study day 9 and was always observed first in hind paws as soft tissue swelling. Fore paws were not affected until 7 days after hind paw swelling became evident. Hind paw diameter peaked by onset +7 days, while paw volume increased until onset + day 10 (data not shown). Significant $(p<0.05)$ body weight loss (compared with healthy control group) developed 2 days after disease onset and progressed through onset +10 days, after which body weight stabilized (data not shown).
Anatomic evidence of arthritis paralleled clinical disease. The earliest evidence of joint involvement was the existence of minimal leukocyte infiltration in the hind paw on the day of disease onset (Fig. 1a). Histologic evidence of inflammation in the paw peaked at 7 and 10 days after onset, and this inflammation then declined modestly through the end of the study (Fig. 1a, c). Bone erosions were significantly $(p<0.05)$ increased in paw sections beginning 2 days after disease onset (Fig. 1b; published previously in [42]) and peaked at 10 days after onset (Fig. 1b, c).

Based on these macroscopic and microscopic patterns, AIA progression was divided into three stages: (1) preclinical (from day -9 before onset to the day of clinically visible arthritis onset [designated day 0]), where evidence of inflammation or bone erosion was lacking; (2) acute clinical (from day 0 to +10 post-onset), where hind paw swelling and body weight loss (macroscopic) as well as inflammation and joint erosion (microscopic) were steadily progressing; and (3) chronic clinical (day +11 post-onset and beyond), where clinical (paw swelling, body weight changes) and structural (inflammation and articular erosions) evidence of joint involvement had reached a plateau.

\section{Hematologic Changes}

Circulating blood cell populations in arthritic animals were altered at all time points, including those taken before joint swelling was first detected (Fig. 2a). Prior to disease onset, mean neutrophil and monocyte numbers were increased, and these populations remained high throughout the study. An increase in "large unstained cells" (thought to be activated lymphocytes [48] or giant granulocytes or monocytes) from $1 \%$ to $3 \%$ was evident during clinical AIA (data not shown). Lymphocytes (both B and $\mathrm{T}$ cells) were reduced prior to onset and remained low during progression. Within the $\mathrm{T}$ cell population, the $\mathrm{CD} 4+/ \mathrm{CD} 8+$ cell ratio was significantly shifted towards $\mathrm{CD} 4+$ helper $\mathrm{T}$ lymphocytes during acute clinical stage of AIA (i.e., between onset and day +5 ; Fig. 2a). This blood signature, where all the subsets of myeloid cell linage were increased, was repeated in the spleen (Fig. 2b). The difference in the CD4+/CD8+ cell ratio in spleen was elevated between onset and onset +4 days (i.e., during acute disease) and remained high through the chronic stage of AIA. The percent but not absolute numbers of $\mathrm{T}(25 \%)$ and B $(27 \%)$ lymphocytes residing in spleen during AIA were significantly lower $(p<0.05$ compared to non-AIA control) than the similar populations in control rats ( $35 \%$ to $40 \%$ for both lymphocyte subsets in non-AIA control).

Hematological and flow cytometric analyses of lymph node cell suspensions revealed that resident leukocyte 

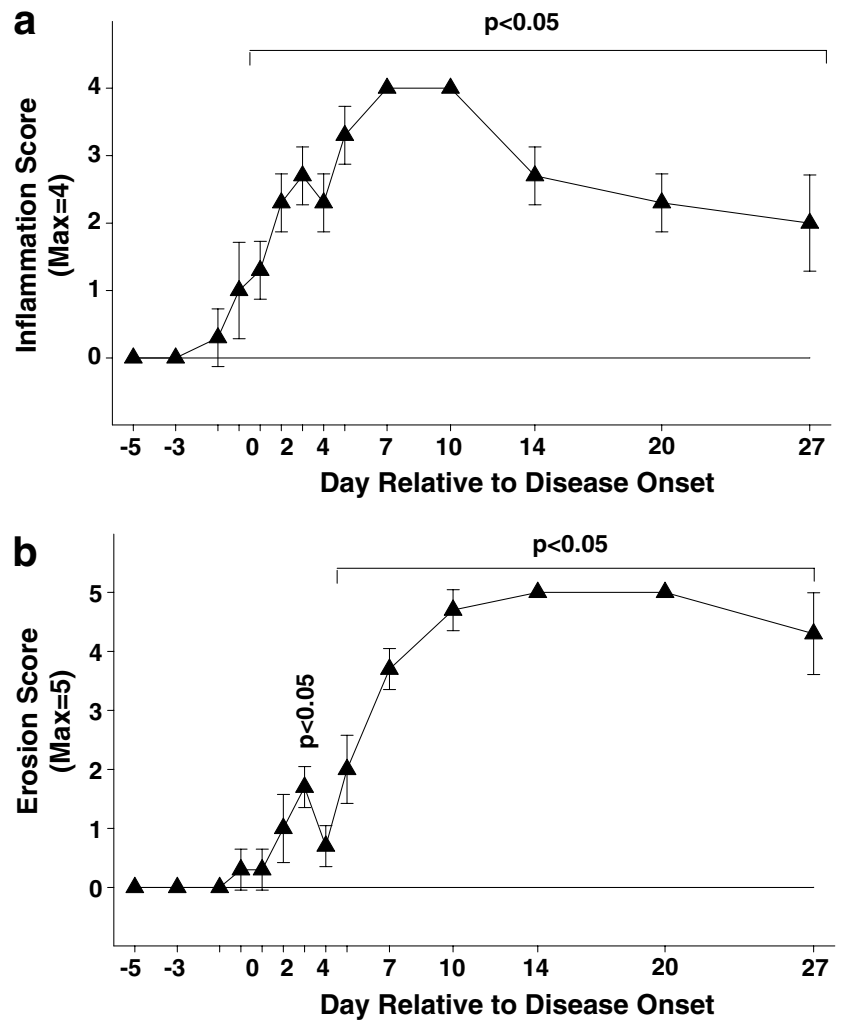

C

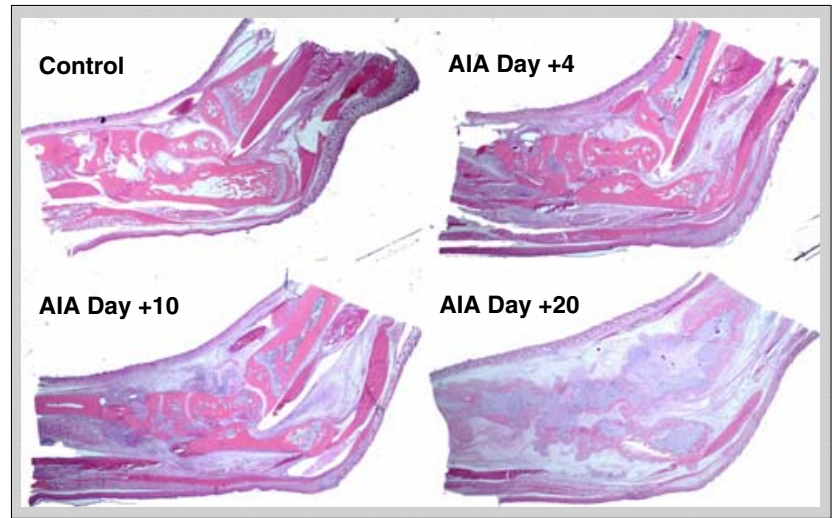

Fig. 1 Progression of adjuvant-induced arthritis in hind paws as indicated by histopathologic scores for inflammation (a) and joint erosion (b) and representative images (c; magnification $=\times 0.5$, stain $=$ $\mathrm{H} \& \mathrm{E})$. Mean $( \pm \mathrm{SEM})$ of arthritic groups (triangles) defined by brackets were significantly different from values of controls (straight line). Onset of clinical disease in the hind paw is designated as day 0 on the $x$-axis. Note: the erosion panel (b) has been reproduced from [42] with permission of the American Society for Bone and Mineral Research

populations (Fig. 3) in local lymph nodes (inguinal and popliteal LNs) were already altered during the preclinical stage of AIA. The mean number of leukocytes residing in inguinal and popliteal LNs rose from $5 \times 10^{6}$ and $0.8 \times 10^{6}$ (basal level in control rats correspondingly) to $39 \times 10^{6}$ (inguinal LN) and $4.4 \times 10^{6}$ (popliteal LN) at 5 days before onset, ultimately peaking at $102 \times 10^{6}$ (inguinal LN) and $25 \times 10^{6}$ (popliteal LN) at the peak of acute AIA (onset +5 days). The cellular composition of draining LNs did not change greatly as AIA progressed; $90 \%$ to $95 \%$ of resident cells in arthritic rats were lymphocytes. Both the absolute numbers and percent composition of myeloid cells (neutrophils and monocytes) in local LNs rose significantly from $3 \%$ (baseline) to $6.7 \%$ at the peak of active disease (7 to 10 days after onset). The absolute number of $\mathrm{B}$ and $\mathrm{T}$ lymphocytes in local nodes of affected rats was significantly elevated at all the stages of AIA progression. In contrast to blood and spleen, the $\mathrm{CD} 4+/ \mathrm{CD} 8+$ ratio in the $\mathrm{T}$ lymphocyte population in local LNs was not changed throughout the course of disease compared to nonarthritic controls (data not shown). The cellularity of distant (mesenteric) LNs was not altered at any stage of disease progression (data not shown).

\section{Systemic Immunoglobulin Changes}

Serum immunoglobulin levels exhibited significant enhancement, with two patterns of expression (Fig. 4). Circulating IgM levels (an efficient activator of the classical complement pathway) and total IgG (the predominant antibody of the secondary immune response) were significantly elevated (two- to eightfold) for the first 3 days after onset (acute stage of AIA). IgG1 and IgG2a (principal elements of Th1- or Th2-type immune responses, respectively [49]) as well as IgG2b followed the same course as total IgG. However, IgE as well as $\operatorname{IgG} 2 \mathrm{c}$ (a comarker together with $\operatorname{IgM}$ for B cell activation in the splenic marginal zone [50]) were significantly amplified throughout the disease, starting with a transient spike initially (tenfold rise for the IgG isoforms, 300-fold for IgE) before partially regressing.

Systemic and Local Changes in Biochemical Markers of Inflammation

Concentrations of selected immune modulators, pro-inflammatory and anti-inflammatory cytokines, and chemokines were measured both systemically (in serum; Fig. 5a) and locally (in hind paw protein extracts; Fig. 5b). Tissue and serum levels exhibited no correlation for several entities, including molecules generally considered to be primary regulators of the pro-inflammatory cascade (e.g., TNF $\alpha$, IL-1, IL-17, IL-6).

In rats, $\alpha 1 \mathrm{AGP}$ is the dominant acute phase protein whereas in human beings, C-reactive protein is more prominent [51]. Concentrations of serum $\alpha 1 \mathrm{AGP}$ were significantly increased throughout the study beginning 5 days before disease onset, and the divergence relative to controls became extreme $(5,000$-fold increase) beginning 
Fig. 2 Changes in leukocyte populations circulating in blood (a) or residing in spleen (b) during AIA progression. Mean $( \pm$ SEM) of arthritic groups encompassed by the bracket were significantly different from controls (horizontal hatched bar represents mean \pm SEM of controls)
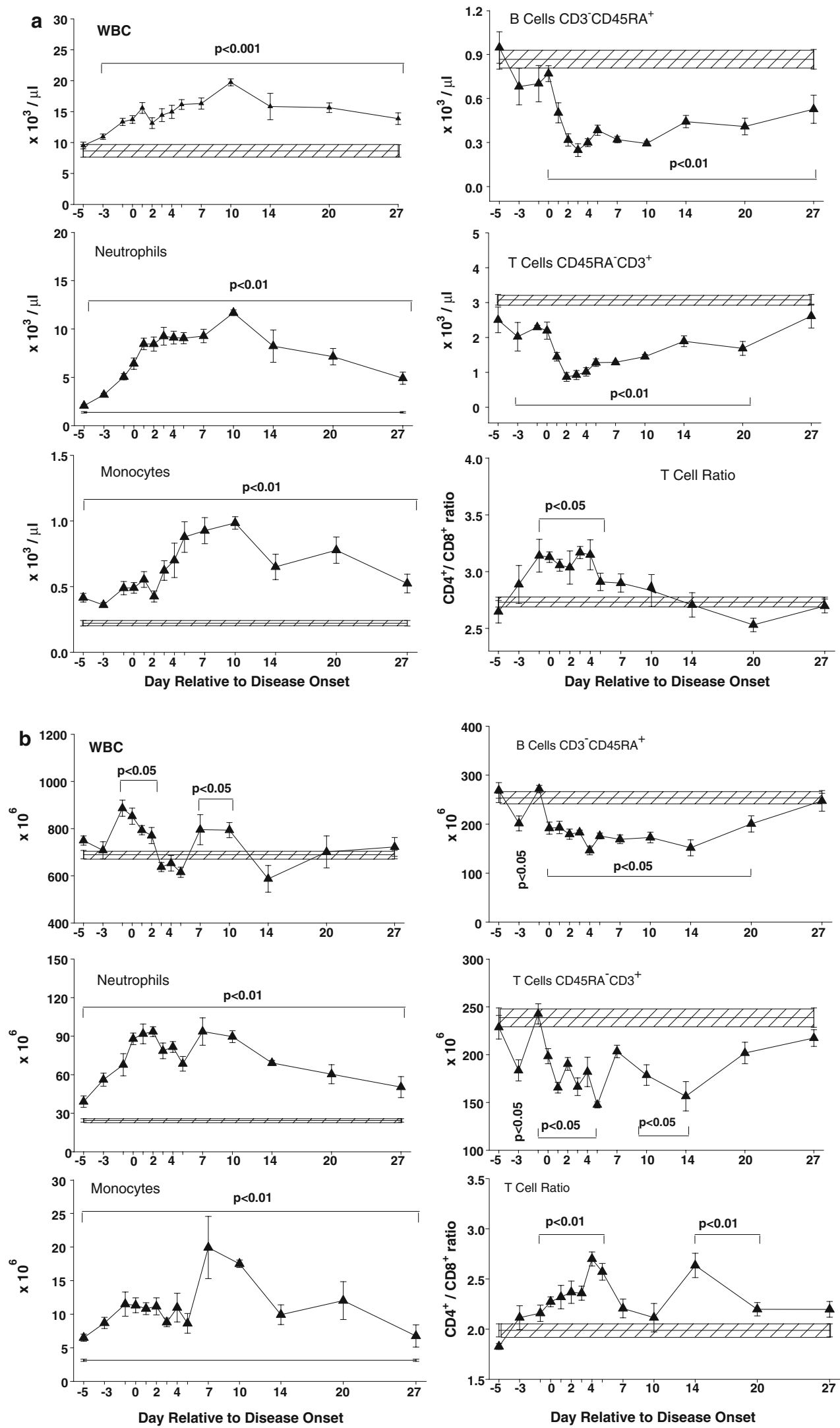
Fig. 3 Changes in leukocyte populations within local lymph nodes (a inguinal and $\mathbf{b}$ popliteal) during AIA progression. Mean $( \pm$ SEM) of arthritic groups encompassed by the bracket were significantly different from controls (horizontal line represents mean \pm SEM of controls) a
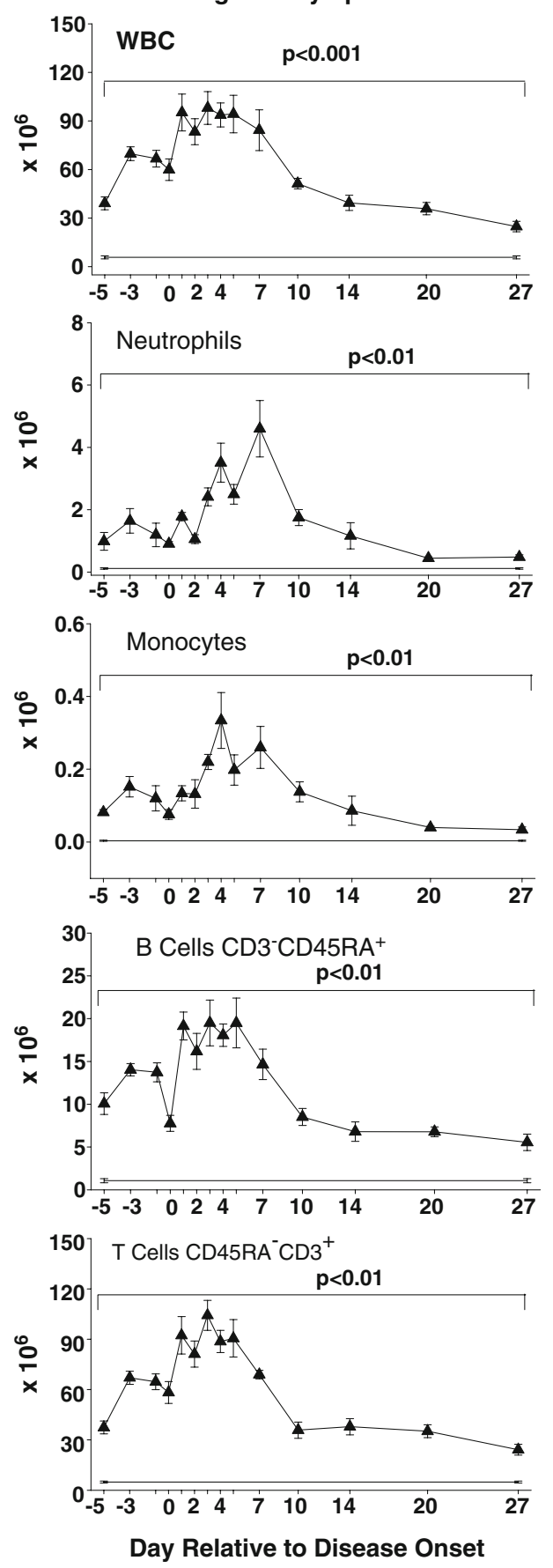

b Popliteal Lymph Node
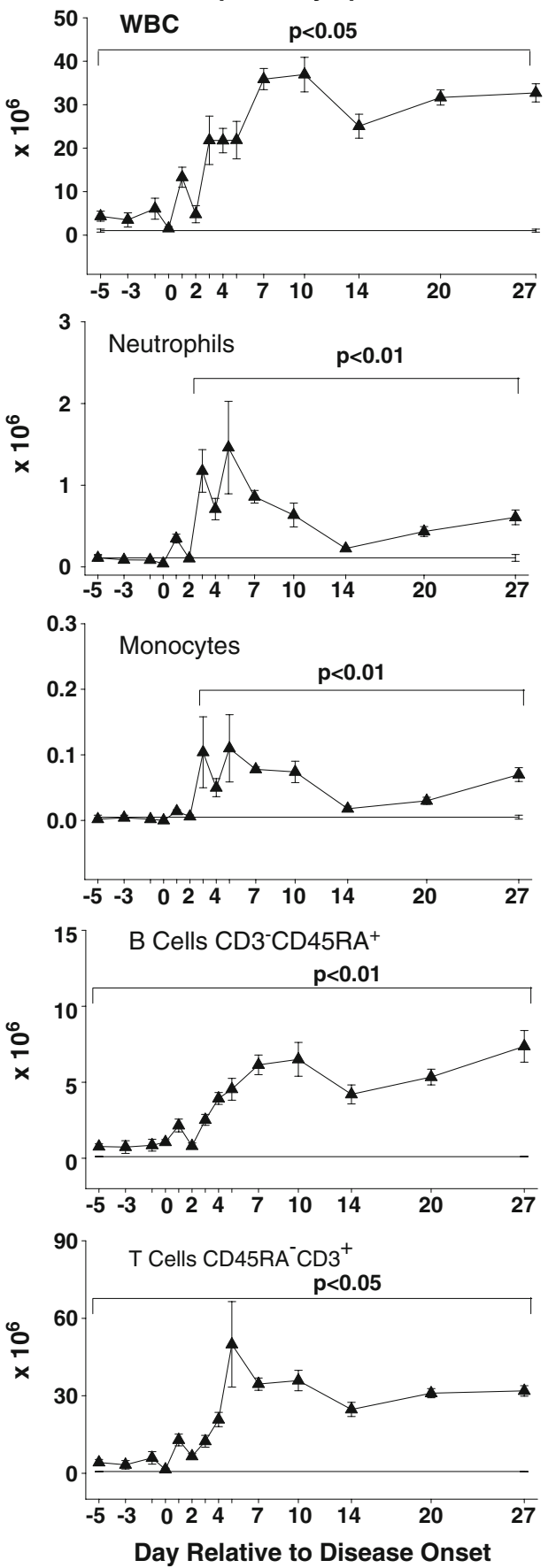

3 days after onset $(2.54 \mathrm{mg} / \mathrm{ml}$; Fig. 5a). Elevated levels of $\alpha 1 \mathrm{AGP}$ were also measurable in paw protein extracts (40$50 \mu \mathrm{g} / \mathrm{mg}$ protein) beginning at onset +3 days.

Serum TNF $\alpha$ concentration was modestly but significantly elevated at $23 \mathrm{pg} / \mathrm{ml}$ beginning 5 days before onset and remained at around this level for most of the study. Serum TNF $\alpha$ exhibited two peaks, one during acute disease at 4 days after onset $(31 \mathrm{pg} / \mathrm{ml})$ and a second at onset +10 days (27 pg/ml). Surprisingly, in joint extracts, TNF $\alpha$ was undetectable (i.e., levels below the assay detection limit of $1 \mathrm{pg} / \mathrm{ml}$ ) throughout the study. This lack was not due to an assay artifact as recombinant rat TNF $\alpha$ could be measured at concentrations as low as $5 \mathrm{pg} / \mathrm{mg}$ total protein when added to paw homogenates (data not shown). This cytokine also was not detected in joints or serum of control rats. By in situ hybridization, a low diffuse TNF $\alpha$ signal was first seen in arthritic hind paws during the acute clinical stage of AIA (beginning at 4 days after onset); TNF $\alpha$ expression was 
Fig. 4 Circulating immunoglobulin levels during AIA progression. Mean $( \pm$ SEM) of arthritic groups encompassed by the bracket were significantly different from controls (horizontal hatched bar represents mean \pm SEM of controls)
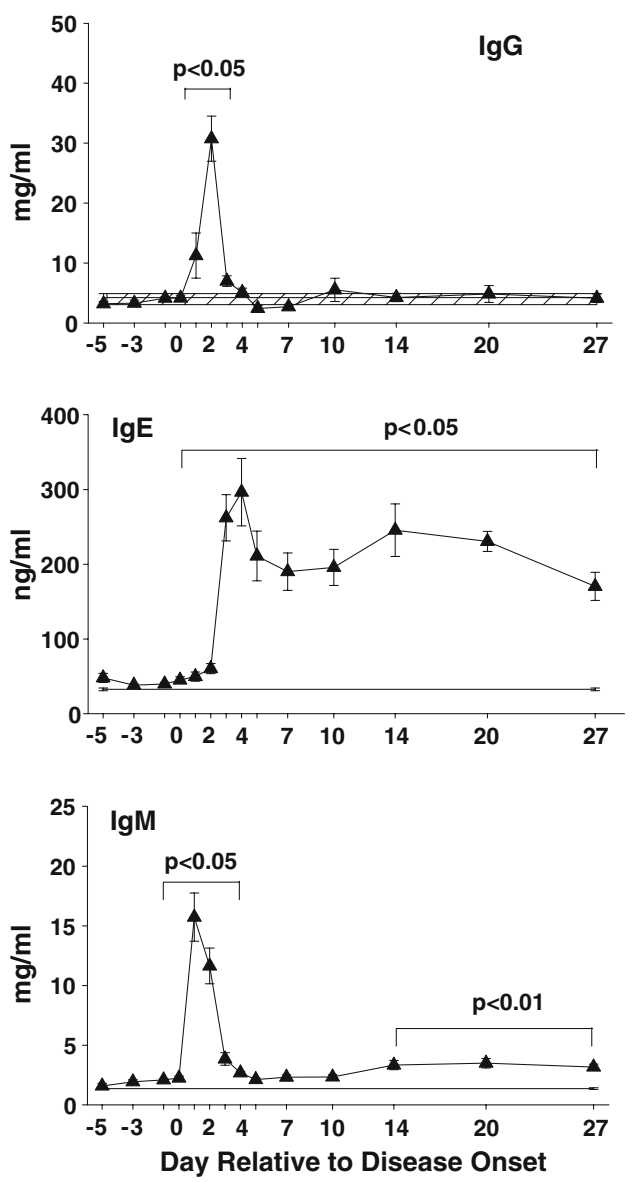
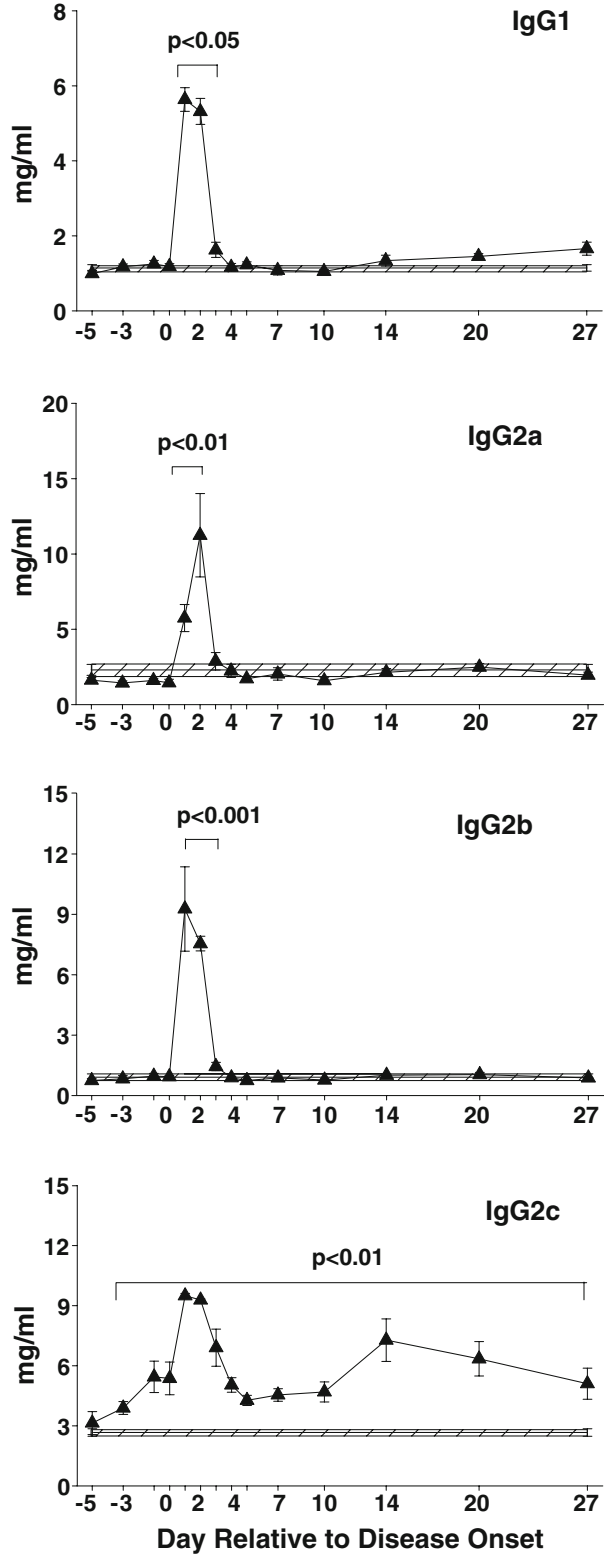

never detected in control paw samples (Fig. 5c). This pattern continued essentially unchanged throughout the chronic clinical stage of AIA, although occasional focal patches of moderate labeling were evident in marrow spaces adjacent to eroding bone (Fig. 5c).

Serum IL-17 was significantly higher in AIA rats as early as 3 days before disease onset (22 to $35 \mathrm{pg} / \mathrm{ml}$ in AIA rats vs. undetectable levels in controls; Fig. 5a). This initial rise in IL-17 presaged a peak concentration of 100 to $150 \mathrm{pg} / \mathrm{ml}$ during the acute phase (from 1 to 7 days after onset) followed by a gradual decline to a lower steady-state level of 32 to $56 \mathrm{pg} / \mathrm{ml}$. In arthritic rats, evidence of increased IL-17 in paw protein extracts was first measurable at onset +2 days after onset; this time coincided with the peak serum concentration, though tissue levels were much lower level (18 pg/mg of total protein). As in serum, IL-17 was not detected (minimal detectable level $>1.6 \mathrm{pg} / \mathrm{ml}$ ) in paw protein extracts from control animals.

IL- $1 \alpha$ was not detected in serum but was significantly increased in AIA paw extracts (203 pg/mg total protein vs. undetectable level in controls) 5 days before disease onset. The tissue concentration of IL- $1 \alpha$ declined substantially by 3 days before onset to $51 \mathrm{pg} / \mathrm{mg}$ of total protein, although this level was still significantly above tissue IL- $1 \alpha$ levels in controls. Incremental but significant increases in tissue IL- $1 \alpha$ (range, 57 to $66 \mathrm{pg} /$ mg total protein) were also detected at early acute AIA (at onset and at day +2) but not thereafter. In contrast, 
Fig. 5 Systemic (a serum) and local (b hind paw protein extract) concentrations of pro- and anti-inflammatory cytokines and chemokines during AIA progression. Mean $( \pm$ SEM) of arthritic groups encompassed by the bracket were significantly different from controls (horizontal hatched bar represents mean \pm SEM of controls). The low intra-articular expression of $\mathrm{TNF} \alpha$ was confirmed by in situ hybridization (c), where signal is generally lacking near the navicular tarsal bone (the principal site of AIA [enclosed by solid square box]) except for small foci of moderate signal (dotted circles) in the marrow and periarticular soft tissues well after AIA onset

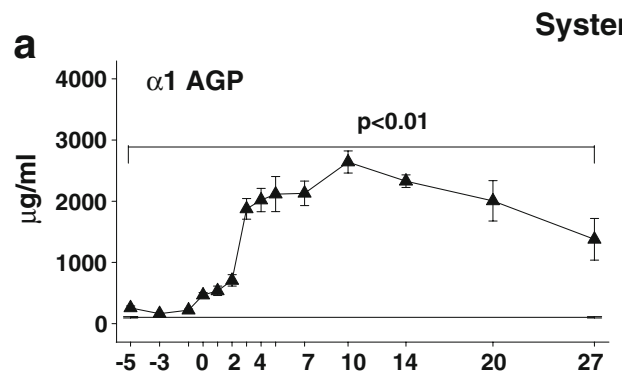

Systemic (serum)
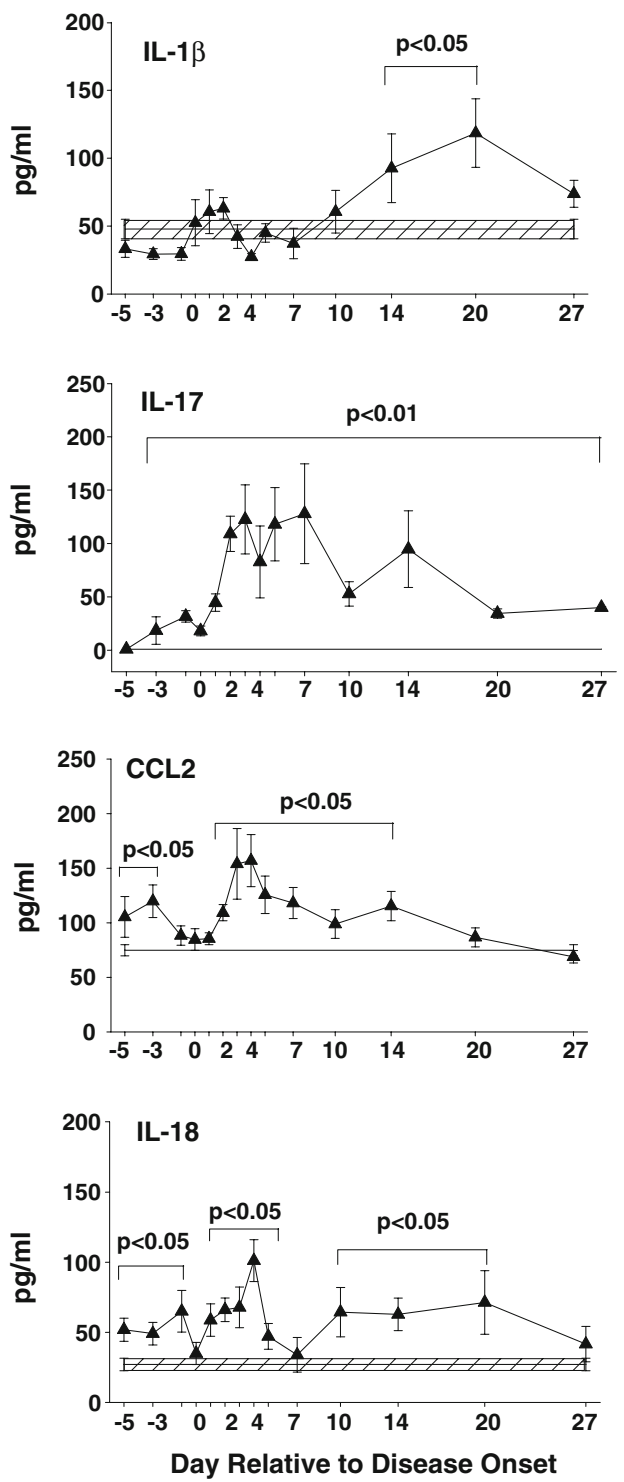
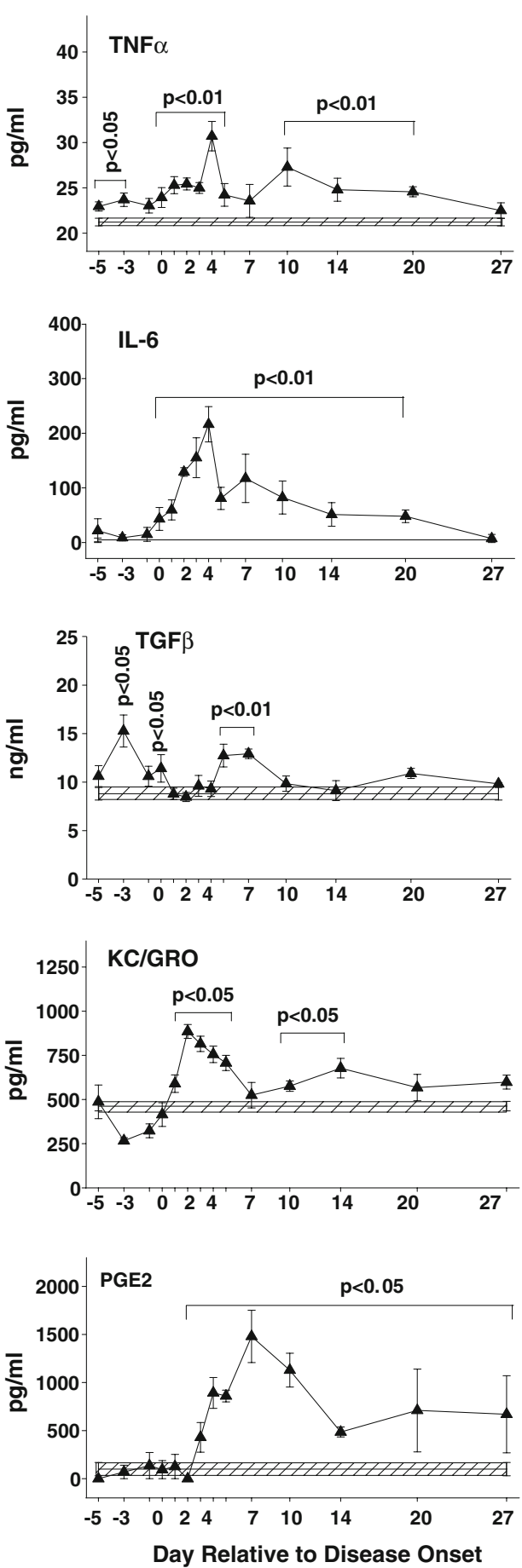

IL-1 $\beta$ in the joint extract first achieved a significant increase at preclinical AIA (3 days prior to AIA onset), after which it rose steeply to peak 3 days after onset at $545 \mathrm{pg} / \mathrm{mg}$ total protein before rapidly declining to a lower steady-state level of 90 to $120 \mathrm{pg} / \mathrm{mg}$ total protein. The serum IL-1 $\beta$ concentration was not significantly increased until onset +14 days, and the peak level
(61 $\mathrm{pg} / \mathrm{ml}$ ) was substantially lower than that measured in paw tissue.

IL-6 cycled in a manner comparable to IL- $1 \beta$. Tissue IL-6 rose rapidly beginning at onset to peak 2 days after onset at $5.9 \mathrm{ng} / \mathrm{mg}$ total protein (vs. undetectable level in controls) before rapidly declining to a lower steady-state range of 0.3 to $0.5 \mathrm{ng} / \mathrm{mg}$ total protein. Serum IL- 6 also increased starting the 
Fig. 5 (continued)
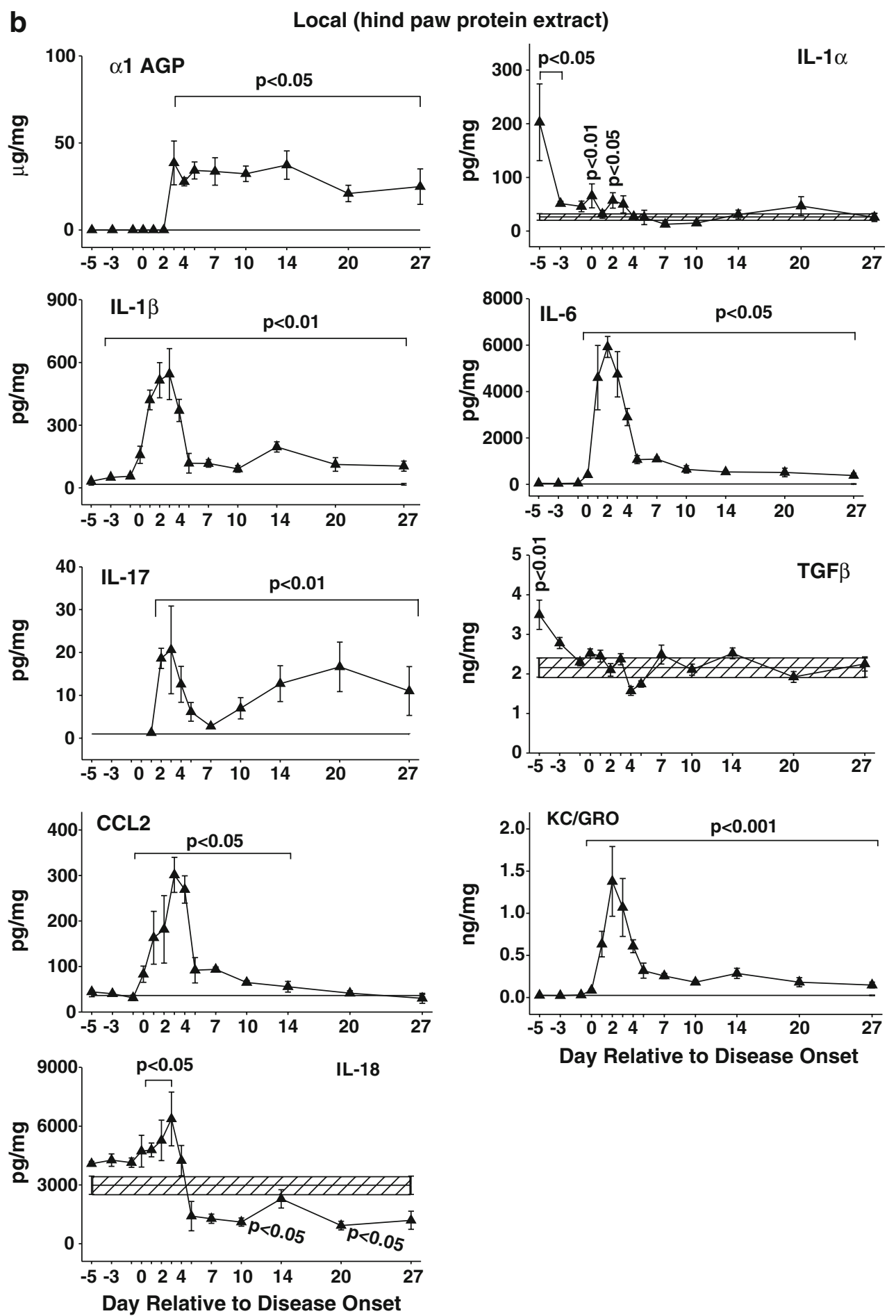

day of disease onset, reaching a lower maximal level (216 pg/ $\mathrm{ml}$ ) at onset +4 days before declining gradually to basal levels. TGF $\beta$ concentrations in serum and paw protein extracts were significantly increased $(p<0.05$ compared to nonarthritic controls) at the preclinical stage of AIA progression and continued to be significantly higher in blood but not paw tissue extracts during acute clinical AIA.
IL-18 was found in greater quantities in AIA tissue (compared with non-AIA control) but persisted for a longer period in blood. Tissue IL-18 was modestly but significantly augmented only from onset +1 to onset +3 days (range, 4.7 to $6.4 \mathrm{ng} / \mathrm{mg}$ total protein), after which levels fell below those detected in control animals. In contrast, significant and persistent elevations in serum IL-18 began 


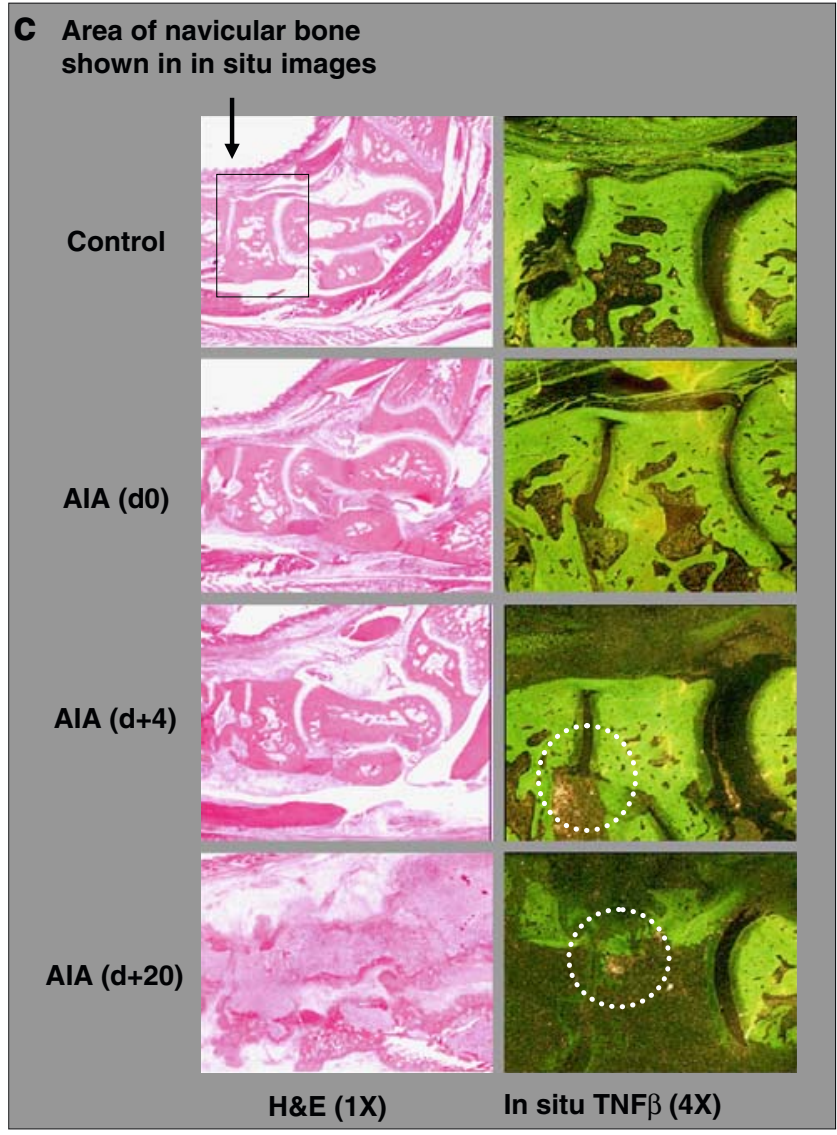

Fig. 5 (continued)

5 days before onset. The peak serum level $(101 \mathrm{pg} / \mathrm{ml})$ occurred at onset +4 days.

Serum CCL2 was transiently but significantly increased 5 and 3 days before disease onset (range, 105 to $120 \mathrm{pg} / \mathrm{ml}$ ), and later from onset to onset +14 days. The peak serum level attained was $157 \mathrm{pg} / \mathrm{ml}$ at onset +4 days. Tissue CCL2 rose rapidly beginning at disease onset to reach a peak level of $301 \mathrm{pg} / \mathrm{mg}$ total protein at onset +3 days before undergoing a swift decrease by onset +10 days.

$\mathrm{KC} / \mathrm{GRO}$ (a chemoattractant and activating factor for neutrophils) followed the same pattern as IL-1 $\beta$ and IL-6. Joint levels increased quickly starting at onset to peak at $1.4 \mathrm{ng} / \mathrm{mg}$ total protein by onset +2 days before rapidly declining to a lower steady-state level $(200 \mathrm{pg} / \mathrm{mg}$ total protein). Serum $\mathrm{KC} / \mathrm{GRO}$ concentrations also began increasing at onset, again achieving a much lower peak level of $885 \mathrm{pg} / \mathrm{ml}$ by 2 days after onset before undergoing a measured decline to levels around $600 \mathrm{pg} / \mathrm{ml}$.

$\mathrm{PGE}_{2}$ was not detected in tissue protein extracts, but serum $\mathrm{PGE}_{2}$ concentration was first significantly elevated 3 days after onset and remained so throughout acute and chronic stages of AIA progression. While IFN $\gamma$ was found to be increased transiently in AIA serum (peaking at $66 \mathrm{pg} / \mathrm{ml}$ between 2 to 5 days after onset), the systemic and local levels of IL-2, IL-4, IL-10, IL-12, and GM-CSF were not changed (compared with the control non-AIA animals) at any examined time point of AIA progression (data not shown).

Systemic and Local Changes in Pro- and Anti-erosive Bone Markers

Systemic and local expression of pro- and anti-erosive bone markers were well correlated (Fig. 6). Local levels of RANKL in paw tissue extracts were markedly increased in AIA rats. As reported previously [42] and reiterated here for context, an initial significant rise at 3 days after onset was followed by sustained elevation (two- to fourfold higher than nonarthritic animals) for 20 days. Serum RANKL was significantly greater 2 days after onset and remained high (up by at least 38\%) throughout the study. In contrast, local OPG levels underwent a significant and sustained decline beginning 1 day after onset $(273 \mathrm{pg} / \mathrm{mg}$ in AIA rats vs. $1,533 \mathrm{pg} / \mathrm{mg}$ in control). Interestingly, OPG levels in serum of arthritic rats were moderately elevated (1.2- to 1.5-fold) throughout the chronic stage of disease (onset +7 days and later; $p<0.05$ ). The local RANKL to OPG ratio in AIA rats was significantly enhanced by 33fold at 1 day after disease onset relative to that in control animals. The disparity in the balance of intra-articular RANKL and OPG climbed rapidly, peaking with a 65 -fold increase over the control ratio 5 days after onset; this divergence persisted for the remainder of the study. By comparison, the serum RANKL/OPG ratio in arthritic rats was much less dramatic with a 2.5 -fold increase vs. control $(p<0.05)$.

\section{Discussion}

In recent years, cytokine and chemokine production in clinical RA has attracted considerable interest since many such molecules are involved in regulating the immune system and its inflammatory response [52]. Numerous cell types in the inflamed synovium of arthritic joints in human patients or animal models can produce cytokines, including recruited leukocytes (activated $\mathrm{T}$ lymphocytes, macrophages, and plasma cells) and resident synovial fibroblasts and endothelial cells [40, 41]. Recent experimental and clinical research with anticytokine biologics confirms that TNF $\alpha$ and IL-1 are dominant mediators of immunemediated joint disease in people $[4,8,9,19,53,54]$ and experimental animals [11-15]. However, the variable efficacy attained in human arthritis patients using existing IL- 1 and TNF $\alpha$ inhibitors coupled with the demonstrated utility of targeting other pro-inflammatory entities [29, 30] clearly suggests that other molecules may also drive 
Fig. 6 Local (hind paw protein extract [left column]) and systemic (serum [right column]) concentrations of bone turnover markers during AIA progression. Mean $( \pm$ SEM) of arthritic groups encompassed by the bracket were significantly different from controls (horizontal hatched bar represents mean \pm SEM of controls). The RANKL panels have been reproduced from [42] with permission of the American Society for Bone and Mineral Research

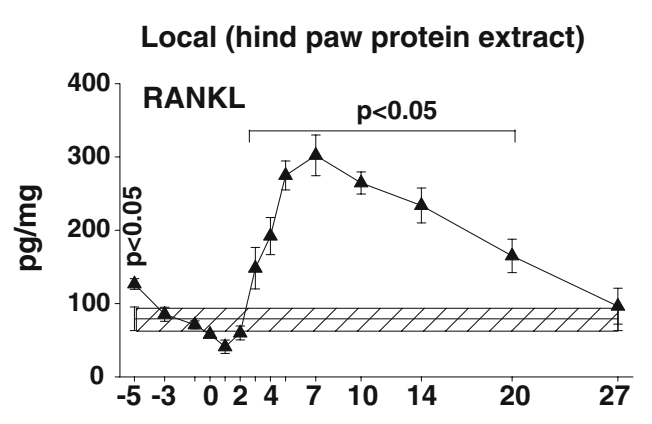

Systemic (serum)
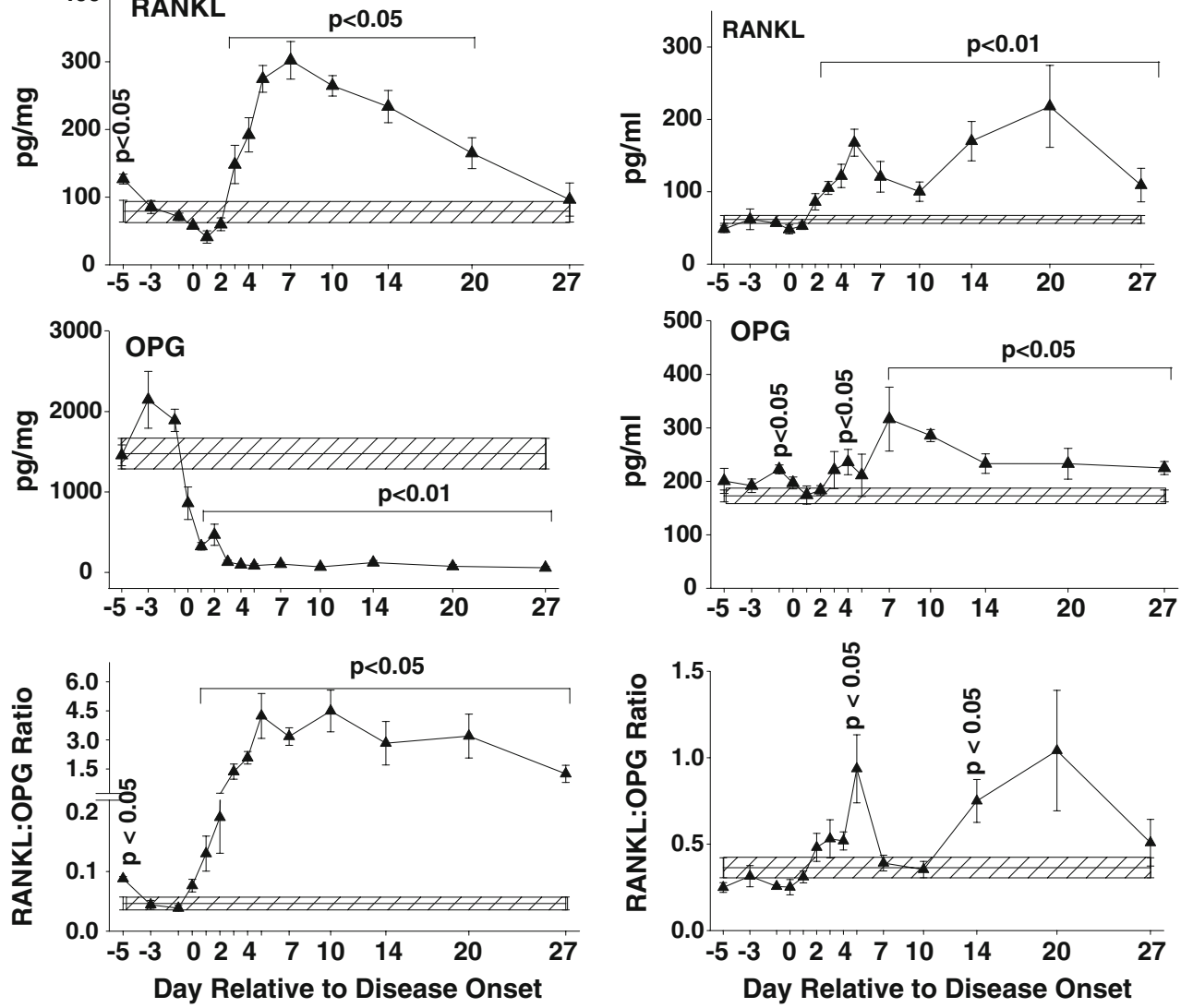

disease. Many pro-inflammatory cytokines (IL-6, IL-12, IL15, IL-18 [for review, see [26]] and IL-17 [25]) and chemokines (CCL2 [27] and CXCL8 [28]) as well as the proresorptive cytokine RANKL [45] have been implicated as potential arthritis mediators based on their presence within inflamed joints or because anticytokine biologics have been shown to reduce disease severity in animal arthritis models [26, 55, 56].

Accordingly, we devised the current experiment in a standard rat AIA model of immune-mediated joint disease to test two hypotheses. First, we predicted that arthritis would be accompanied by unique local (joint and regional lymph nodes) and systemic (serum and distant lymphoid tissues) combinations of cytokine patterns and altered leukocyte populations characterized by modest to no overlap in their compositions. Second, we posited that intra-articular concentrations of one or more other proinflammatory molecules in addition to IL- 1 and $\mathrm{TNF} \alpha$ would be so elevated during preclinical and/or early clinical stages of disease that these entities could also be assigned roles as major players in the induction and maintenance of AIA. An anticipated corollary outcome of these two hypotheses was that serum biomarker signatures of joint disease might not truly reflect the most important mediators in joint tissues. Our results confirm that these two hypotheses as well as the corollary conclusions are accurate.

In accord with our first hypothesis, the biochemical and cellular compositions in the local compartments and systemically were substantially different. This conclusion is supported by two lines of evidence. First and foremost, the two major pro-inflammatory cytokines were confined to separate compartments; IL-1 was restricted entirely $(\alpha$ variant) or mostly ( $\beta$ form) to arthritic joints, while detectable protein level of $\mathrm{TNF} \alpha$ was limited to serum (Fig. 5). This compartmentalization of IL-1 locally and TNF systemically is consistent with prior experiments demonstrating that joint destruction and osteoclast formation are more predominant with local application of IL-1 [57]. Instillation of IL-1 into the joint but not $\mathrm{TNF} \alpha$ augments osteoclast numbers locally [20], and anti-IL-1 but not anti-TNF biologic therapy has been shown to inhibit angiogenesis in hind paws of rats with AIA [10]. Systemic TNF $\alpha$ augments the process by releasing osteogenic precursors from the bone marrow and by 'priming' them to respond to RANKL [58, 59]. This interpretation is 
further supported as a general principle for pro-arthritic signaling molecules by our prior demonstration that different systemic and local concentrations of RANKL (a TNF superfamily member that is an essential mediator of bone erosions) were strongly correlated with the induction of divergent degrees of systemic and local osteopenia in rats with AIA starting as early as the day of disease onset $[24,42]$. Secondly, the nature of the inflammatory changes differed in regional lymph nodes (inguinal, popliteal) relative to more distant lymphoid tissues (mesenteric lymph nodes, spleen). Regional lymph nodes as well as the splenic white pulp exhibited reactive hyperplasia, but the regional nodes responded earlier and more robustly (Figs. 2b and 3). This anatomic distinction was reflected in absolute cell counts, as local nodes contained significantly more neutrophils, monocytes, and lymphocytes (mainly B cells; Fig. 3), while more distant nodes did not (data not shown). Interestingly, the significant influx of $\mathrm{B}$ and $\mathrm{T}$ cells into local lymph nodes coincided with the peak of immunoglobulin levels in AIA serum (Fig. 4) but was the reverse of the situation in spleen, where these two populations of lymphocytes were reduced relative to those in control rats (Fig. 2b). These unique biochemical and cellular signatures first began developing well before AIA onset (Figs. 2, 3, and 5). Furthermore, increases in concentrations of several pro-inflammatory mediators were profound in serum and/or

Table II Comparison of systemic and local changes in biomarkers relative to the progression of rat AIA

\begin{tabular}{|c|c|c|c|c|c|c|}
\hline \multirow{3}{*}{ Marker } & \multicolumn{3}{|c|}{$\begin{array}{l}\text { AIA vs. Control } \\
\text { (SERUM) }\end{array}$} & \multicolumn{3}{|c|}{ AIA vs. Control (PAW) } \\
\hline & \multirow{2}{*}{$\begin{array}{l}\text { Pre- } \\
\text { clin }\end{array}$} & \multicolumn{2}{|c|}{ Clinical } & \multirow{2}{*}{$\begin{array}{l}\text { Pre- } \\
\text { clin }\end{array}$} & \multicolumn{2}{|c|}{ Clinical } \\
\hline & & Acute & Chronic & & Acute & Chronic \\
\hline$\alpha 1 \mathrm{AGP}$ & $M$ & $M$ & $M$ & $=$ & $M$ & $M$ \\
\hline TNF $\alpha$ & $\triangle$ & $\triangle$ & $\triangle$ & $=$ & $\triangle$ & $\triangle$ \\
\hline IL-1 $\alpha$ & $=$ & $=$ & $=$ & $\triangle$ & $\triangle$ & $=$ \\
\hline IL-1 $\beta$ & $=$ & $=$ & $\triangle$ & $\triangle$ & $\triangle$ & $\triangle$ \\
\hline IL-17 & $M$ & $M$ & $M$ & $=$ & W & $M$ \\
\hline TGF $\beta$ & $\triangle$ & $\triangle$ & $=$ & $\triangle$ & $=$ & $=$ \\
\hline CCL2 & $\triangle$ & 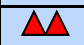 & $\triangle$ & $=$ & W & $=$ \\
\hline IL-6 & $=$ & $M$ & $M$ & $=$ & $\mathrm{W}$ & $M$ \\
\hline IL-18 & 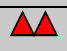 & $M$ & $M$ & $=$ & $\triangle$ & $=$ \\
\hline KC/GRO & $=$ & $\triangle$ & $\triangle$ & $=$ & $M$ & $M$ \\
\hline PGE2 & $=$ & $M$ & $M$ & $=$ & $=$ & $=$ \\
\hline RANKL & $=$ & $\triangle$ & $M$ & $=$ & $M$ & $M$ \\
\hline OPG & $=$ & $\triangle$ & $\triangle$ & $=$ & $w$ & 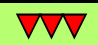 \\
\hline RANKL/OPG & $=$ & $\triangle$ & $\triangle$ & $=$ & $M$ & $M$ \\
\hline TRACP-5B [42] & $=$ & $=$ & $=$ & $=$ & $M$ & $M$ \\
\hline
\end{tabular}

$=$ No changes, one triangle $1.3-$ to $>2$-fold change, two triangles $2-$ to $>3$-fold change, three triangles $\geq 3$-fold change, red detected by protein assay, yellow detected by in situ hybridization paw protein extracts (Table II): acute phase protein $\alpha 1 \mathrm{AGP}$ (20-fold greater), CCL2 (100-fold more), IL-18 (50-fold higher), IL-17 (from undetectable levels in control animals to $100-150 \mathrm{pg} / \mathrm{ml}$ in AIA rats), TGF $\beta$ (2.4 times higher), and TNF $\alpha$ (up by $10-30 \%$ ). The fact that these molecules were elevated before the onset of clinical AIA positions them as potentially critical mediators and/or markers of disease induction, a supposition made stronger by our demonstration that this pro-inflammatory signature coincided with dramatically increased levels of IL- 1 and TGF $\beta$ in paw protein extracts (Table II).

Our second hypothesis, that elevated cytokine levels before onset and/or during early clinical disease would identify a given molecule as a participant in the induction and maintenance of joint disease, also appears to be true for several of the entities measured in the current experiment. The most intriguing such finding was high serum (systemic) concentrations of IL-17 before AIA onset. This discovery strongly bolsters the proposed role for IL-17, a pro-inflammatory cytokine produced by $\mathrm{CD} 4+\mathrm{T}$ cells, as a potent inducer and enhancer of inflammation and damage in the RA joint $[60,61]$. Several cytokines capable of inducing the differentiation of Th1 $\mathrm{T}$ cells into IL-17producing $\mathrm{T}$ cells (Th17)-TGF $\beta$, IL-1, TNF $\alpha$, IL-18were all elevated systemically or/and locally before AIA onset in the present experiment. The site where Th1 and/or Th17 cells were induced to differentiate and expand into pathogenic effector cells in rheumatoid arthritis is not known yet, but the fact that at the preclinical stage of AIA the CD4+/CD8+ T cell ratio is shifted toward the CD4+ subset systemically (blood and spleen) but not locally (within draining inguinal and popliteal LNs) permits the speculation that Th17 $\mathrm{T}$ cells are transformed into pathogenic effectors systemically and then circulate widely, including regular forays into the sites of local inflammation (i.e., joints). Furthermore, a synergistic effect among IL-17, IL-1, TGF $\beta$, and TNF $\alpha$ could drive differentiation, maturation, activation, and cytokine release by neutrophils, monocytes, and synovial fibroblasts [60,62, 63], thereby leading eventually to the visible onset of clinical arthritis in RA patients and experimental animals.

The second molecule which our current experiment identified as a potential major player in the induction of AIA was CCL2, which was highly elevated in serum of AIA rats during the preclinical stage of disease progression. CCL2 is chemotactic for monocytes and T cells, and it has been detected at high levels in synovial fibroblasts from RA patients [64], especially in response to IL-1 and TNF $\alpha$. Presumably, the main function of CCL2 during the preclinical stage of AIA will be to recruit circulating monocytes to become tissue macrophages within the joint. This premise is supported by the increased absolute number of monocytes within the circulation (Fig 2a) as well as local 
lymph nodes (Fig. 3) and the spleen (Fig. 2b) long before AIA onset.

Our demonstration that (1) levels of many mediators other than IL-1 and TNF $\alpha$ [10, 12, 57, 65] undergo pronounced alterations over time before and during AIA and that (2) the chemokine/cytokine availability in local and systemic compartments is divergent (Table II) strongly implies that cytokine action is partitioned in both time and space. For example, IL-1 $\alpha$ was found only in joints, while $\mathrm{TNF} \alpha$ and $\mathrm{PGE}_{2}$ were elevated only in serum. Some molecules were accentuated chiefly during the early phases of AIA evolution (e.g., CCL2, IL- $1 \alpha$, IL-1 $\beta$, IL-6, and KC/ GRO in joints; IL-17, CCL-2, IFN- $\gamma$, IL-6, and KC/GRO in serum), others were found most prominently during the later periods (e.g., IL-1 $\beta$ in serum), and still others exhibited either intermittent spikes or relatively consistent elevations that compassed the entire study (e.g., IL-18 and $\mathrm{TNF} \alpha$ in serum). Presumably, arthritis is driven mainly by soaring tissue levels of pro-inflammatory mediators, while systemic inflammation is impelled by amplified circulating levels. This supposition, if true, implicates IL-1 (both forms), IL-6, IL-17, CCL2, and possibly KC/GRO as the key local signals for inciting joint lesions in AIA. Previous work implicating IL-18 [26] and TNF $\alpha$ [54] as possible mediators in rheumatoid arthritis suggests that these two molecules should receive further study as potential players in AIA, even though they were not detected in afflicted joints in this study.

This argument regarding pro-inflammatory mediators is readily extrapolated to molecules that specifically regulate bone turnover, such as RANKL (a marker and mediator of enhanced bone resorption capacity) and OPG (which prevents bone resorption and preserves bone). Analysis of synovial tissue from patients with active RA demonstrated a lack of OPG expression in conjunction with significant RANKL expression [66, 67]. Our current time-course data (Fig. 6) convincingly showed that the onset of a major imbalance in the intra-articular RANKL to OPG ratio- the consequence of exacerbated RANKL production in conjunction with a precipitous OPG decline-coincided with the earliest evidence of bone destruction in arthritic joints. Concentrations of OPG protein in rats had not been described in the literature previous to this study due to the lack of available rat OPG assays. The novel finding of suppressed OPG levels in arthritic paws was facilitated by our identification of a commercially available luminexbased singleplex mouse OPG assay that strongly crossreacted with recombinant rat OPG standards. Prior to this discovery, conclusions regarding the possible impact of elevated total RANKL levels in rats were tempered by the lack of corresponding information on OPG levels. The RANKL to OPG ratio is considered an important determinant of bone resorption in arthritis [68]. The new ability to quantify OPG and RANKL in rats is an important advance due to the widespread use of rats as models for investigating human bone disease. As a first application, we determined (Table II) that the local reduction in intraarticular OPG protein levels and the associated increase in the RANKL to OPG ratio coincided with significant local increases in intra-articular osteoclast numbers and levels of the osteoclast marker TRACP-5b [42]. Given the extreme proresorptive state associated with the local increase in RANKL to OPG ratio, we posit that RANKL is the primary driver of bone erosion in AIA. Other molecules such as IL$1 \beta$, IL-17, and TNF $\alpha$ might promote further bone destruction by recruiting preosteoclasts and promoting osteoclast differentiation [69-71] and/or by modulating RANKL and OPG levels [72-74]. The dominance of RANKL in mediating bone erosions is further supported by the ability of OPG to cause greater suppression of bone erosions compared to inhibitors of TNF $\alpha$ or IL-1, even when OPG treatment is undertaken in the presence of severe ongoing joint inflammation [11, 23].

Our current data showing that measurement of serum RANKL appears to offer a good means of monitoring the progression of bone erosion once disease has become clinically established. Additional work with rheumatoid arthritis patients will be needed to define what other systemic markers of bone resorption would be suitable markers for following early disease [75].

Data from this study suggest that the measurement of serum biomarkers may not adequately predict whether or not a patient will respond to a given anticytokine biologic. While sampling of synovial tissue or fluid from arthritic patients could help to tailor appropriate therapies, this is probably an impractical routine. Our results may provide scientific justification for the current clinical practice of employing frontline cytokine inhibitors in rotation until an optimal disease-modifying response is obtained. The rationale for this empirical approach is that intra-articular increases in certain cytokines might not be evident in the peripheral circulation, where diagnostic samples are typically collected. These results provide a framework for the evaluation and validation of new and existing therapeutic targets by identifying the spatial and temporal expression of numerous cytokines and other factors thought to be involved in the progression of inflammatory arthritis.

\section{Conclusions}

These data have provided substantial new insights regarding the molecular pathogenesis that initiates and perpetuates AIA in rats. The design of our study has afforded us new understanding of the main phases of AIA - premonitory (preclinical), initiation (acute [day of onset to onset + 
10 days]), and maintenance (chronic [onset +11 days and beyond]) - as well as an initial view of some molecular events that appear to drive each stage. Our AIA experiment has revealed that local damage in affected joints is initiated and sustained principally by the pro-inflammatory molecules IL- 1 (both $\alpha$ and $\beta$ forms), IL-6, TGF $\beta$, IL-17, and CCL2 along with the pro-erosive entity RANKL (coupled with a marked decline in the bone-protective RANKL inhibitor, OPG), while systemic manifestations of inflammation are driven by TNF $\alpha$, IL-17, IL-18, TGF $\beta$, CCL2, $\mathrm{PGE}_{2}$, and acute phase proteins. The evaluation of serum RANKL should be considered as an appropriate biomarker of ongoing but not imminent bone erosion. We hope that improved understanding of arthritis mechanisms afforded by these AIA data will enhance our collective abilities to define new targets and diagnostic tests that may be translated into useful new avenues for treating immunemediated joint diseases in human patients.

Acknowledgements The authors thank Janet Buys, Yan Cheng, Chris De La Torre, Darlene Kratavil, Ruiyuan A. Luo, Efrain Pacheco, and Li Zhu for technical assistance. Amy Foreman-Wykert of Amgen Inc. provided editorial assistance.

Open Access This article is distributed under the terms of the Creative Commons Attribution Noncommercial License which permits any noncommercial use, distribution, and reproduction in any medium, provided the original author(s) and source are credited.

\section{References}

1. Firestein GS. Evolving concepts of rheumatoid arthritis. Nature. 2003;423:356-61. doi:10.1038/nature01661.

2. Arend WP, Dayer JM. Cytokines and cytokine inhibitors or antagonists in rheumatoid arthritis. Arthritis Rheum. 1990;33: 305-15. doi:10.1002/art.1780330302.

3. Taylor PC. Anti-cytokines and cytokines in the treatment of rheumatoid arthritis. Curr Pharm Des. 2003;9:1095-106. doi:10. 2174/1381612033454991.

4. Arend WP, Dayer JM. Inhibition of the production and effects of interleukin-1 and tumor necrosis factor alpha in rheumatoid arthritis. Arthritis Rheum. 1995;38:151-60. doi:10.1002/art. 1780380202.

5. Brennan FM, Field M, Chu CQ, Feldmann M, Maini RN. Cytokine expression in rheumatoid arthritis. Br J Rheumatol. 1991;30(Suppl 1):76-80. doi:10.1093/rheumatology/30.1.76.

6. Keller C, Webb A, Davis J. Cytokines in the seronegative spondyloarthropathies and their modification by TNF blockade: a brief report and literature review. Ann Rheum Dis. 2003;62:1128-32. doi:10.1136/ard.2003.011023.

7. Roberts S, Butler RC. Inflammatory mediators as potential therapeutic targets in the spine. Curr Drug Targets Inflamm Allergy. 2005;4:257-66. doi:10.2174/1568010053586372.

8. Bresnihan B, Varo-Gracia JM, Cobby M, Doherty M, Domljan Z, Emery P, Nuki G, Pavelka K, Rau R, Rozman B, Watt I, Williams B, Aitchison R, McCabe D, Musikic P. Treatment of rheumatoid arthritis with recombinant human interleukin-1 receptor antagonist. Arthritis Rheum. 1998;41:2196-204. doi:10.1002/1529-0131 (199812)41:12<2196::AID-ART15>3.0.CO;2-2.
9. Richard-Miceli C, Dougados M. Tumour necrosis factor-alpha blockers in rheumatoid arthritis: review of the clinical experience. BioDrugs. 2001;15:251-9. doi:10.2165/00063030-200115040-00005.

10. Coxon A, Bolon B, Estrada J, Kaufman S, Scully S, Rattan A, et al. Inhibition of interleukin-1 but not tumor necrosis factor suppresses neovascularization in rat models of corneal angiogenesis and adjuvant arthritis. Arthritis Rheum. 2002;46:2604-12. doi:10.1002/art.10546.

11. Feige U, Hu YL, Gasser J, Campagnuolo G, Munyakazi L, Bolon B. Anti-interleukin-1 and anti-tumor necrosis factor-alpha synergistically inhibit adjuvant arthritis in Lewis rats. Cell Mol Life Sci. 2000;57:1457-70. doi:10.1007/PL00000629.

12. Joosten LA, Helsen MM, Saxne T, van de Loo FA, Heinegard D, van den Berg WB. IL-1 alpha beta blockade prevents cartilage and bone destruction in murine type II collagen-induced arthritis, whereas TNF-alpha blockade only ameliorates joint inflammation. J Immunol. 1999;163:5049-55.

13. Kuiper S, Joosten LA, Bendele AM, Edwards CK III, Arntz OJ, Helsen MM, et al. Different roles of tumour necrosis factor alpha and interleukin 1 in murine streptococcal cell wall arthritis. Cytokine. 1998;10:690-702. doi:10.1006/cyto.1998.0372.

14. Wooley PH, Dutcher J, Widmer MB, Gillis S. Influence of a recombinant human soluble tumor necrosis factor receptor FC fusion protein on type II collagen-induced arthritis in mice. J Immunol. 1993;151:6602-7.

15. Wooley PH, Whalen JD, Chapman DL, Berger AE, Richard KA, Aspar DG, et al. The effect of an interleukin-1 receptor antagonist protein on type II collagen-induced arthritis and antigen-induced arthritis in mice. Arthritis Rheum. 1993;36:1305-14. doi:10.1002/ art. 1780360915.

16. Breedveld FC. Future trends in the treatment of rheumatoid arthritis: cytokine targets. Rheumatology (Oxford). 1999;38(Suppl 2):11-3. doi:10.1093/rheumatology/38.suppl_1.11.

17. Calabrese LH. Molecular differences in anticytokine therapies. Clin Exp Rheumatol. 2003;21:241-8.

18. Kourbeti IS, Boumpas DT. Biological therapies of autoimmune diseases. Curr Drug Targets Inflamm Allergy. 2005;4:41-6. doi:10.2174/1568010053622812.

19. Brennan FM, Maini RN, Feldmann M. Role of pro-inflammatory cytokines in rheumatoid arthritis. Springer Semin Immunopathol. 1998;20:133-47. doi:10.1007/BF00832003.

20. Bolon B, Campagnuolo G, Zhu L, Duryea D, Zack D, Feige U. Interleukin-1beta and tumor necrosis factor-alpha produce distinct, time-dependent patterns of acute arthritis in the rat knee. Vet Pathol. 2004;41:235-43. doi:10.1354/vp.41-3-235.

21. Joosten LA, Helsen MM, van de Loo FA, van den Berg WB. Anticytokine treatment of established type II collagen-induced arthritis in DBA/1 mice. A comparative study using anti-TNF alpha, anti-IL-1 alpha/beta, and IL-1Ra. Arthritis Rheum. 1996;39:797-809. doi:10.1002/art.1780390513.

22. Marinova-Mutafchieva L, Williams RO, Mason LJ, Mauri C, Feldmann M, Maini RN. Dynamics of proinflammatory cytokine expression in the joints of mice with collagen-induced arthritis (CIA). Clin Exp Immunol. 1997;107:507-12. doi:10.1046/j.13652249.1997.2901181.x.

23. Campagnuolo G, Bolon B, Feige U. Kinetics of bone protection by recombinant osteoprotegerin therapy in Lewis rats with adjuvant arthritis. Arthritis Rheum. 2002;46:1926-36. doi:10.1002/ art.10369.

24. Schett G, Middleton S, Bolon B, Stolina M, Brown H, Zhu L, et al. Additive bone-protective effects of anabolic treatment when used in conjunction with RANKL and tumor necrosis factor inhibition in two rat arthritis models. Arthritis Rheum. 2005;52: 1604-11. doi:10.1002/art.21021.

25. Gaffen SL. Biology of recently discovered cytokines: interleukin17 - a unique inflammatory cytokine with roles in bone biology 
and arthritis. Arthritis Res Ther. 2004;6:240-7. doi:10.1186/ $\operatorname{ar} 1444$.

26. McInnes IB, Gracie JA. Targeting cytokines beyond tumor necrosis factor-alpha and interleukin-1 in rheumatoid arthritis. Curr Rheumatol Rep. 2004;6:336-42. doi:10.1007/s11926-004-0007-2.

27. Rollins BJ. Monocyte chemoattractant protein 1: a potential regulator of monocyte recruitment in inflammatory disease. Mol Med Today. 1996;2:198-204. doi:10.1016/1357-4310(96)88772-7.

28. Punzi L, Calo L, Plebani M. Clinical significance of cytokine determination in synovial fluid. Crit Rev Clin Lab Sci. 2002;39:63-88. doi:10.1080/10408360290795448.

29. Koller MD. Targeted therapy in rheumatoid arthritis. Wien Med Wochenschr. 2006;156:53-60. doi:10.1007/s10354-005-0245-6.

30. Kulmatycki KM, Jamali F. Drug disease interactions: role of inflammatory mediators in disease and variability in drug response. J Pharm Pharmaceut Sci. 2005;8:602-25.

31. McInnes IB, Gracie JA. Targeting cytokines beyond tumor necrosis factor-alpha and interleukin-1 in rheumatoid arthritis. Curr Pain Headache Rep. 2005;9:405-11. doi:10.1007/s11916-005-0020-9.

32. Bolon B, Shalhoub V, Kostenuik PJ, Campagnuolo G, Morony S, Boyle WJ, et al. Osteoprotegerin, an endogenous antiosteoclast factor for protecting bone in rheumatoid arthritis. Arthritis Rheum. 2002;46:3121-35. doi:10.1002/art.10680.

33. Crotti TN, Smith MD, Weedon H, Ahern MJ, Findlay DM, Kraan $\mathrm{M}$, et al. Receptor activator NF-kappaB ligand (RANKL) expression in synovial tissue from patients with rheumatoid arthritis, spondyloarthropathy, osteoarthritis, and from normal patients: semiquantitative and quantitative analysis. Ann Rheum Dis. 2002;61:1047-54. doi:10.1136/ard.61.12.1047.

34. Kong YY, Feige U, Sarosi I, Bolon B, Tafuri A, Morony S, et al. Activated $\mathrm{T}$ cells regulate bone loss and joint destruction in adjuvant arthritis through osteoprotegerin ligand. Nature. 1999;402:304-9. doi:10.1038/46303.

35. Pettit AR, Ji H, von SD, Muller R, Goldring SR, Choi Y, Benoist C, Gravallese EM. TRANCE/RANKL knockout mice are protected from bone erosion in a serum transfer model of arthritis. Am J Pathol. 2001;159:1689-99.

36. Romas E, Sims NA, Hards DK, Lindsay M, Quinn JW, Ryan PF, et al. Osteoprotegerin reduces osteoclast numbers and prevents bone erosion in collagen-induced arthritis. Am J Pathol. 2002;161:1419-27.

37. Redlich K, Hayer S, Maier A, Dunstan CR, Tohidast-Akrad M, Lang S, et al. Tumor necrosis factor alpha-mediated joint destruction is inhibited by targeting osteoclasts with osteoprotegerin. Arthritis Rheum. 2002;46:785-92. doi:10.1002/art.10097.

38. Schett G, Redlich K, Hayer S, Zwerina J, Bolon B, Dunstan C, et al. Osteoprotegerin protects against generalized bone loss in tumor necrosis factor-transgenic mice. Arthritis Rheum. 2003;48:204251. doi:10.1002/art.11150.

39. Cohen SB, Dore RK, Lane NE, Ory PA, Peterfy CG, Sharp JT, van der HD, Zhou L, Tsuji W, Newmark R. Denosumab treatment effects on structural damage, bone mineral density, and bone turnover in rheumatoid arthritis: a twelve-month, multicenter, randomized, double-blind, placebo-controlled, phase II clinical trial. Arthritis Rheum. 2008;58:1299-309. doi:10.1002/art.23417.

40. Andreakos ET, Foxwell BM, Brennan FM, Maini RN, Feldmann M. Cytokines and anti-cytokine biologicals in autoimmunity: present and future. Cytokine Growth Factor Rev. 2002;13:299313. doi:10.1016/S1359-6101(02)00018-7.

41. Arend WP. Physiology of cytokine pathways in rheumatoid arthritis. Arthritis Rheum. 2001;45:101-6. doi:10.1002/15290131(200102)45:1<101::AID-ANR90>3.0.CO;2-7.

42. Stolina M, Adamu S, Ominsky M, Dwyer D, Asuncion F, Geng Z, et al. RANKL is a marker and mediator of local and systemic bone loss in two rat models of inflammatory arthritis. J Bone Miner Res. 2005;20:1756-65. doi:10.1359/JBMR.050601.
43. Rosengren S, Firestein GS, Boyle DL. Measurement of inflammatory biomarkers in synovial tissue extracts by enzyme-linked immunosorbent assay. Clin Diagn Lab Immunol. 2003;10:100210. doi:10.1128/CDLI.10.6.1002-1010.2003.

44. Steiner G, Tohidast-Akrad M, Witzmann G, Vesely M, StudnickaBenke A, Gal A, et al. Cytokine production by synovial T cells in rheumatoid arthritis. Rheumatology (Oxford). 1999;38:202-13. doi:10.1093/rheumatology/38.3.202.

45. Bolon B, Campagnuolo G, Feige U. Duration of bone protection by a single osteoprotegerin injection in rats with adjuvant-induced arthritis. Cell Mol Life Sci. 2002;59:1569-76. doi:10.1007/ s00018-002-8530-7.

46. Bolon B, Morony S, Cheng Y, Hu YL, Feige U. Osteoclast numbers in Lewis rats with adjuvant-induced arthritis: identification of preferred sites and parameters for rapid quantitative analysis. Vet Pathol. 2004;41:30-6. doi:10.1354/vp.41-1-30.

47. Targan SR, Shanahan F, Karp LC. Inflammatory bowel disease: from bench to bedside. 2nd ed. New York City: Springer; 2005.

48. Harmening DM. Clinical hematology and fundamentals of homeostasis. 2nd ed. Philadelphia: Davis; 1991.

49. Kaplan C, Valdez JC, Chandrasekaran R, Eibel H, Mikecz K, Glant TT, et al. Th1 and Th2 cytokines regulate proteoglycanspecific autoantibody isotypes and arthritis. Arthritis Res. 2002;4:54-8. doi:10.1186/ar383.

50. Oliver AM, Martin F, Gartland GL, Carter RH, Kearney JF. Marginal zone B cells exhibit unique activation, proliferative and immunoglobulin secretory responses. Eur J Immunol. 1997;27:2366-74. doi:10.1002/eji.1830270935.

51. Petersen HH, Nielsen JP, Heegaard PM. Application of acute phase protein measurements in veterinary clinical chemistry. Vet Res. 2004;35:163-87. doi:10.1051/vetres:2004002.

52. Miossec P. An update on the cytokine network in rheumatoid arthritis. Curr Opin Rheumatol. 2004;16:218-22. doi:10.1097/ 00002281-200405000-00009.

53. Feldmann M, Brennan FM, Maini RN. Role of cytokines in rheumatoid arthritis. Annu Rev Immunol. 1996;14:397-440. doi:10.1146/annurev.immunol.14.1.397.

54. Maini RN, Taylor PC, Paleolog E, Charles P, Ballara S, Brennan FM, et al. Anti-tumour necrosis factor specific antibody (infliximab) treatment provides insights into the pathophysiology of rheumatoid arthritis. Ann Rheum Dis. 1999;58(Suppl 1): I56-60.

55. Lubberts E, Koenders MI, van den Berg WB. The role of T-cell interleukin-17 in conducting destructive arthritis: lessons from animal models. Arthritis Res Ther. 2005;7:29-37. doi:10.1186/ar1478.

56. Schulze-Koops H, Kalden JR. The balance of Th1/Th2 cytokines in rheumatoid arthritis. Best Pract Res Clin Rheumatol. 2001;15:677-91. doi:10.1053/berh.2001.0187.

57. van den Berg WB. Joint inflammation and cartilage destruction may occur uncoupled. Springer Semin Immunopathol. 1998;20:149-64. doi:10.1007/BF00832004.

58. Li P, Schwarz EM, O'Keefe RJ, Ma L, Boyce BF, Xing L. RANK signaling is not required for TNFalpha-mediated increase in CD11 (hi) osteoclast precursors but is essential for mature osteoclast formation in TNFalpha-mediated inflammatory arthritis. J Bone Miner Res. 2004;19:207-13. doi:10.1359/JBMR.0301233.

59. Ochi S, Shinohara M, Sato K, Gober HJ, Koga T, Kodama T, et al. Pathological role of osteoclast costimulation in arthritis-induced bone loss. Proc Natl Acad Sci U S A. 2007;104:11394-9. doi:10.1073/pnas.0701971104.

60. Miossec P. Interleukin-17 in rheumatoid arthritis: if T cells were to contribute to inflammation and destruction through synergy. Arthritis Rheum. 2003;48:594-601. doi:10.1002/art.10816.

61. Steinman L. A brief history of $\mathrm{T}(\mathrm{H}) 17$, the first major revision in the $\mathrm{T}(\mathrm{H}) 1 / \mathrm{T}(\mathrm{H}) 2$ hypothesis of $\mathrm{T}$ cell-mediated tissue damage. Nat Med. 2007;13:139-45. doi:10.1038/nm1551. 
62. Cheon H, Yu SJ, Yoo DH, Chae IJ, Song GG, Sohn J. Increased expression of pro-inflammatory cytokines and metalloproteinase-1 by TGF-beta1 in synovial fibroblasts from rheumatoid arthritis and normal individuals. Clin Exp Immunol. 2002;127:547-52. doi:10.1046/j.1365-2249.2002.01785.x.

63. Kehlen A, Thiele K, Riemann D, Langner J. Expression, modulation and signalling of IL-17 receptor in fibroblast-like synoviocytes of patients with rheumatoid arthritis. Clin Exp Immunol. 2002;127:539-46. doi:10.1046/j.1365-2249.2002.01782.x.

64. Szekanecz Z, Kim J, Koch AE. Chemokines and chemokine receptors in rheumatoid arthritis. Semin Immunol. 2003;15:15-21. doi:10.1016/S1044-5323(02)00124-0.

65. van den Berg W. Cytokines in bone and cartilage destruction and repair. J Clin Rheumatol. 2001;7:S8-11.

66. Haynes D, Crotti T, Weedon H, Slavotinek J, Au V, Coleman M, et al. Modulation of RANKL and osteoprotegerin expression in synovial tissue from patients with rheumatoid arthritis in response to diseasemodifying antirheumatic drug treatment and correlation with radiologic outcome. Arthritis Rheum. 2008;59:911-20. doi:10.1002/ art.23818.

67. Skoumal M, Kolarz G, Haberhauer G, Woloszczuk W, Hawa G, Klingler A. Osteoprotegerin and the receptor activator of NFkappa B ligand in the serum and synovial fluid. A comparison of patients with longstanding rheumatoid arthritis and osteoarthritis. Rheumatol Int. 2005;26:63-9. doi:10.1007/s00296-0040579-1.

68. Geusens PP, Landewe R, Garnero P, Chen D, Dunstan CR, Lems $\mathrm{WF}$, et al. The ratio of circulating osteoprotegerin to RANKL in early rheumatoid arthritis predicts later joint destruction. Arthritis Rheum. 2006;54:1772-7. doi:10.1002/art.21896.
69. Kindle L, Rothe L, Kriss M, Osdoby P, Collin-Osdoby P. Human microvascular endothelial cell activation by IL-1 and TNF-alpha stimulates the adhesion and transendothelial migration of circulating human CD14+ monocytes that develop with RANKL into functional osteoclasts. J Bone Miner Res. 2006;21:193-206. doi:10.1359/JBMR.051027.

70. Lam J, Takeshita S, Barker JE, Kanagawa O, Ross FP, Teitelbaum SL. TNF-a induces osteoclastogenesis by direct stimulation of macrophages exposed to permissive levels of RANK ligand. J Clin Invest. 2000;106:1481-8. doi:10.1172/JCI11176.

71. Wei S, Kitaura H, Zhou P, Ross FP, Teitelbaum SL. IL-1 mediates TNF-induced osteoclastogenesis. J Clin Invest. 2005;115:282-90.

72. Hofbauer LC, Lacey DL, Dunstan CR, Spelsberg TC, Riggs BL, Khosla S. Interleukin- $1 \mathrm{~b}$ and tumor necrosis factor-a, but not interleukin 6, stimulate osteoprotegerin ligand gene expression in human osteoblastic cells. Bone. 1999;25:255-9. doi:10.1016/S87563282(99)00162-3.

73. Koenders MI, Lubberts E, Oppers-Walgreen B, van den Bersselaar L, Helsen MM, Di Padova F, et al. Blocking of interleukin-17 during reactivation of experimental arthritis prevents joint inflammation and bone erosion by decreasing RANKL and interleukin1. Am J Pathol. 2005;167:141-9.

74. Lubberts E, van den Bersselaar L, Oppers-Walgreen B, Schwarzenberger P, Coenen-de Roo C, Kolls JK, et al. IL-17 promotes bone erosion in murine collagen-induced arthritis through loss of the receptor activator of NF-kB ligand/osteoprotegerin balance. J Immunol. 2003; 170:2655-62.

75. McInnes IB, Schett G. Cytokines in the pathogenesis of rheumatoid arthritis. Nat Rev Immunol. 2007;7:429-42. doi:10. 1038/nri2094. 